\title{
Magnetic Processing of Diamagnetic Materials
}

\author{
Masafumi Yamato ${ }^{1, *}$ and Tsunehisa Kimura ${ }^{2,3}$ (D) \\ 1 Department of Applied Chemistry, Tokyo Metropolitan University,1-1 Minami-ohsawa, Hachioji, \\ Tokyo 192-0397, Japan \\ 2 Division of Forestry and Biomaterials, Kyoto University, Sakyo-ku, Kyoto 606-8502, Japan; \\ tkimura@kais.kyoto-u.ac.jp \\ 3 Fukui University of Technology, 3-6-1 Gakuen, Fukui 910-8505, Japan \\ * Correspondence: yamato-masafumi@tmu.ac.jp
}

Received: 4 June 2020; Accepted: 1 July 2020; Published: 3 July 2020

check for updates

\begin{abstract}
Currently, materials scientists and nuclear magnetic resonance spectroscopists have easy access to high magnetic fields of approximately $10 \mathrm{~T}$ supplied by superconducting magnets. Neodymium magnets that generate magnetic fields of approximately $1 \mathrm{~T}$ are readily available for laboratory use and are widely used in daily life applications, such as mobile phones and electric vehicles. Such common access to magnetic fields—unexpected 30 years ago-has helped researchers discover new magnetic phenomena and use such phenomena to process diamagnetic materials. Although diamagnetism is well known, it is only during the last 30 years that researchers have applied magnetic processing to various classes of diamagnetic materials such as ceramics, biomaterials, and polymers. The magnetic effects that we report herein are largely attributable to the magnetic force, magnetic torque, and magnetic enthalpy that in turn, directly derive from the well-defined magnetic energy. An example of a more complex magnetic effect is orientation of crystalline polymers under an applied magnetic field; researchers do not yet fully understand the crystallization mechanism. Our review largely focuses on polymeric materials. Research topics such as magnetic effect on chiral recognition are interesting yet beyond our scope.
\end{abstract}

Keywords: magnetic force; magnetic torque; separation; particle manipulation and patterning; crystallization; magnetic dipole-dipole interaction; orientation; levitation; thermodynamics

\section{Introduction}

Most polymeric and other materials are diamagnetic. Diamagnetism is well known [1-4] but was long thought to have little effect on polymeric materials. This perspective began to change 30 years ago, when superconducting magnets became readily accessible to material scientists and engineers. The magnetic field generated by superconducting magnets is $10 \times$ stronger than those generated by electromagnets and permanent magnets. The magnetic effect produced by superconducting magnets is $100 \times$ larger than that of other magnets because the magnetic energy - the origin of the magnetic effect-is proportional to the square of the intensity of the magnetic field. Interesting applications of superconducting magnets-possible only because of the use of high magnetic fields - include magnetic levitation [5-7] and the Moses effect [8]. Researchers have extensively studied the physical [9], chemical [10,11], and biological [12] effects of magnetic fields. The magnetic effects on polymeric materials were applied to polymer processing $[13,14]$.

Most magnetic effects can be understood in terms of the magnetic energy. The magnetic energy of diamagnetic materials is usually very small and hence, may be difficult to disentangle from other energies such as thermal, gravitational, electric, and elastic [15]. In our review, we explain various diamagnetic phenomena in terms of magnetic energy. We cover magnetic effects on diamagnetic 
materials in general, with a focus on applications to polymeric materials. Research on polymer composites containing ferromagnetic particles [16] is important, but is beyond our scope.

This article is organized as follows: Section 2 presents the magnetic energy origin of the magnetic effect. Although the magnetic energy of diamagnetic materials is much smaller than that of ferromagnetic materials, it is still effective. We discuss the feasibility of the magnetic effect under appropriate conditions. Section 3 provides the basics of magnetic force. We discuss the basic equations for levitation and separation of diamagnetic materials using magnetic force. As an application of magnetic force, we present a two-dimensional pattern formation of fine particles and crystal growth under levitation. Section 4 provides the basics of magnetic torque. We show the basic equation of the magnetic torque, which is the origin of magnetic orientation, and discuss orientation control of materials with uniaxial and biaxial symmetry. We also discuss the time constant of orientation. In Section 5, we focus on magnetic dipole-dipole interactions and review applications of ferromagnetic dipole-dipole interactions. In Section 6, we discuss the effect on phase transition temperature expressed by the Magneto-Clapeyron equation. The temperature change estimated from the equation is extremely small, but researchers observe a larger temperature change in some experiments. Sections 7 and 8 consist of magnetic orientation under a phase transition-crystallization and microphase separation, respectively. We discuss in detail the origin of the anisotropic structures contributing to orientation. The origin of magnetic orientation under a phase transition is still an open question. Finally, in Section 9 , we summarize and present perspectives on magnetic processing of diamagnetic materials.

\section{Magnetic Energy}

The diamagnetic properties of materials are attributable to the magnetic susceptibility, $\chi$ : approximately $-10^{-5}$ to $-10^{-6}$ for diamagnetic materials and approximately $10^{3}$ for ferromagnetic materials. A microparticle with volume $V$ placed in a magnetic field $B$ has a magnetic energy $E_{\text {mag }}$ expressed by:

$$
E_{\text {mag }}=-\frac{\chi V B^{2}}{2 \mu_{0}}
$$

where $\mu_{0}$ is the magnetic permeability of vacuum. The magnetic energy of diamagnetic materials is elevated under a magnetic field because $\chi$ is negative. For example, when $\chi=-10^{-6}, B=10 \mathrm{~T}$, and $V=(0.1 \mu \mathrm{m})^{3}, E_{\text {mag }}=4 \times-10^{-21} \mathrm{~J}$, which is compared to this energy value to the thermal energy $k_{\mathrm{B}} T=4 \times-10^{-20} \mathrm{~J}$ at $T=300 \mathrm{~K}$, where $k_{\mathrm{B}}$ is the Boltzmann constant. This gives rise to the Boltzmann factor $e^{-10}$, indicating that a microparticle of this volume is almost completely repelled against Brownian motion by applying a magnetic field of $10 \mathrm{~T}$ [17].

Figure 1 shows the magnetic energy for various values of $|\chi| V$ as a function of the magnetic field [13]. When $B>0.1 \mathrm{~T}$, the magnetic energy exceeds the thermal energy if $|\chi| V>10^{-24}$. Because typical values of $\chi$ are approximately $-10^{-6}, V>1 \mu \mathrm{m}^{3}$. This indicates that microparticles can be manipulated by weak magnetic fields as low as $0.1 \mathrm{~T}$, which electromagnets and permanent magnets readily supply. However, fillers, nucleating agents, and other materials added to polymers are usually larger than the micrometer scale. Thus, we expect that micrometer-scale polymer additives can be manipulated using relatively weak magnetic fields. With much stronger magnetic fields, much smaller additives can be manipulated. Additionally, heterogeneous structures-such as those appearing during crystallization of semi-crystalline polymers and microphase separation of block copolymers-are susceptible to and influenced by the magnetic field. This will be described in detail in the following sections. 


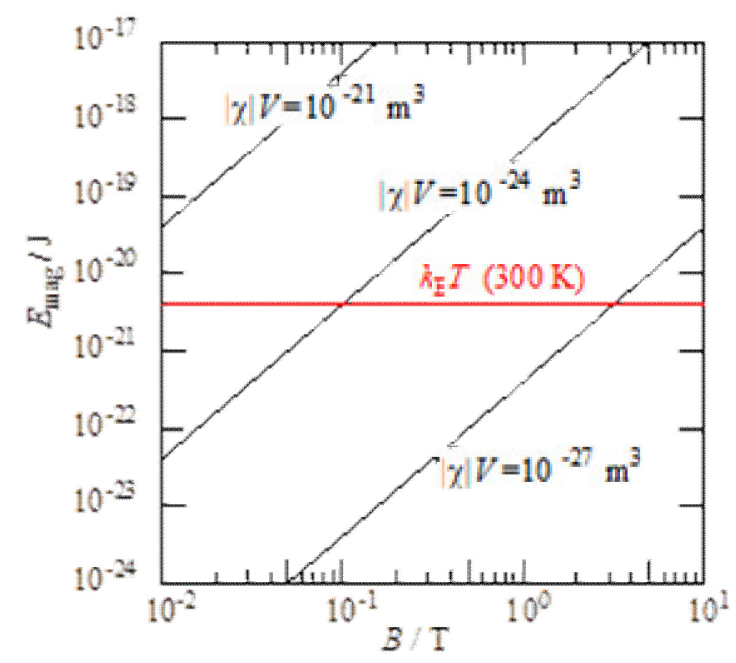

Figure 1. Magnetic energy $E_{\text {mag }}$ as a function of magnetic field $B$. Thermal energy $k_{\mathrm{B}} T$ at $300 \mathrm{~K}$ is shown in the figure.

\section{Magnetic Force}

If a particle is placed in a spatially inhomogeneous magnetic field, a force is exerted on it. Because the magnetic energy of the diamagnetic particle is elevated in the area where the magnetic field is stronger, the force acts on the particle in a manner that pushes it from a high field area to a low field area. This magnetic force is expressed by:

$$
F=-\nabla E_{\mathrm{mag}}=\frac{\chi V}{2 \mu_{0}} \nabla B^{2}
$$

The intensity of the gradient term is further expressed as $\left(\chi / \mu_{0}\right) B d B / d z$ in the case of one dimension [18]. The magnetic field gradient generated by a permanent magnet is usually not sufficiently intense to cause a considerable repulsive force-such as that used to levitate diamagnetic particles-because the diamagnetic susceptibility is as small as $-10^{-6}$ [5]. However, a strong magnetic field such as that produced by a superconducting magnet can produce a repulsive force that is sufficient to levitate diamagnetic particles.

\subsection{Levitation}

Consider a diamagnetic particle subjected to a vertical magnetic field gradient. Gravitational and magnetic forces act on the particle. If the magnetic force is sufficiently large to balance the gravitational force, the particle levitates. The corresponding equation (Figure 2a) is expressed by:

$$
\rho_{1} g=\frac{\chi_{1}}{\mu_{0}} B \frac{d B}{d z}
$$

where $\chi_{1}$ and $\rho_{1}$ are the susceptibility and density of the particle, respectively; $g$ is the gravitational acceleration. Some examples are as follows. Researchers have reported magnetic levitation of various organic materials. Water levitates under conditions with a gradient field of $B d B / d z=1360 \mathrm{~T}^{2} / \mathrm{m}$ that a typical superconducting magnet does not generate. Various areas of science and technology use magnetic levitation [19-22]. 


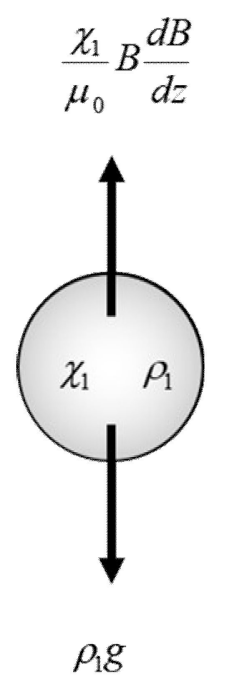

(a)

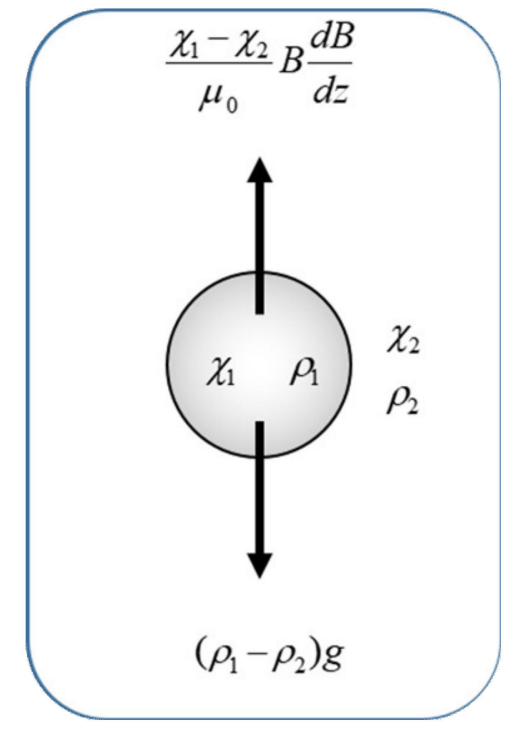

(b)

Figure 2. The force acting on a particle with susceptibility $\chi_{1}$ and density $\rho_{1}$ levitating in (a) vacuum and in (b) a medium with $\chi_{2}$ and $\rho_{2}$.

If a particle is surrounded by a liquid medium, two additional forces should be added to Equation (3) - the hydrodynamic and magnetic buoyancies exerted by the liquid medium (Figure 2b). Then, Equation (3) is modified as:

$$
\left(\rho_{1}-\rho_{2}\right) g=\frac{\left(\chi_{1}-\chi_{2}\right)}{\mu_{0}} B \frac{d B}{d z}
$$

where $\rho_{2}$ is the density of the medium (causing the hydrodynamic buoyancy) and $\chi_{2}$ is the susceptibility of the medium (causing the magnetic buoyancy). The magnetic term in Equation (4) strongly depends on the value of $\chi_{2}$. Earnshaw's law shows that $\chi_{1}-\chi_{2}<0$ should be satisfied for stable levitation. If the medium is paramagnetic or ferromagnetic $\left(\chi_{2}>0\right)$ and the particle is diamagnetic $\left(\chi_{1}<0\right)$, this condition is inherently satisfied. Gold is floated in cryogenic oxygen [23]. Researchers regard a paramagnetic particle to be diamagnetic if the particle is immersed in a liquid matrix, where the susceptibility of the matrix is larger than that of the particle. Ikezoe et al. achieved stable levitation of paramagnetic substances $\left(\chi_{1}>0\right)$ in accordance with Earnshaw's law [24]. This is termed the magneto Archimedes effect, which is useful when using weak magnetic fields and is widely used to enhance an apparent magnetic force [25,26].

The microgravity environment created by magnetic levitation enables the shape of a liquid droplet to be highly spherical because of non-contacting support. For example, researchers prepared a glass sphere with high sphericity by melting inorganic glass with a laser in a levitation environment [27]. Researchers also polymerized a monomer droplet, levitating in a paramagnetic liquid with a magnetic field of $1 \mathrm{~T}$, to obtain a highly spherical polymer (Figure 3) [28]. 


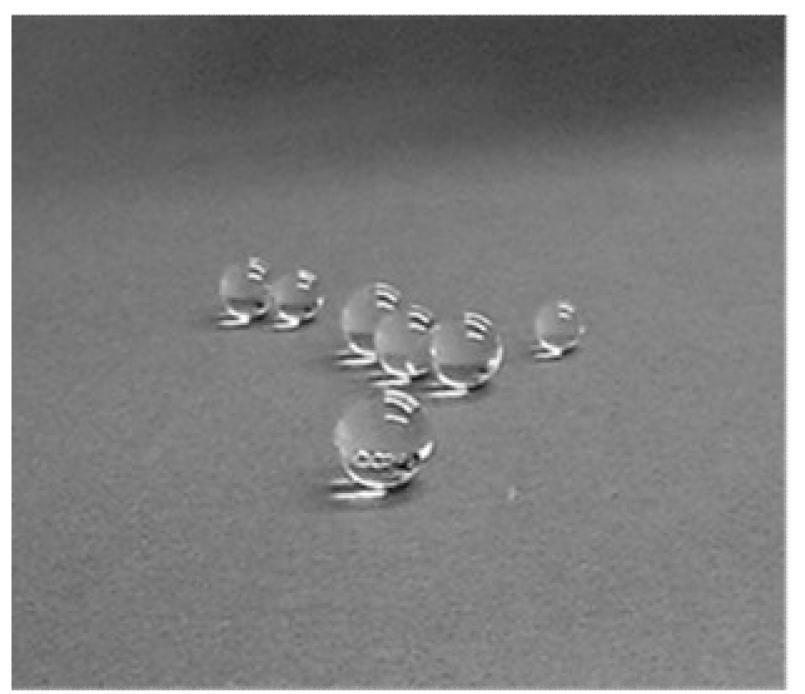

Figure 3. Large poly(benzyl methacrylate) spheres fabricated by levitation polymerization. The size of the sphere is 7 to $9 \mathrm{~mm}$ in diameter.

\subsection{Separation}

The location of stable levitation of a particle depends on the particle's density and magnetic susceptibility, and the profile of the magnetic field. Researchers separate polymer pellets-atactic polystyrene, poly(ethylene terephthalate), poly(methyl methacrylate), syndiotactic polypropylene, and styrene-butadiene block copolymer-by using the magneto Archimedes effect in an electromagnet [29]. Researchers have also separated polyethylene and polypropylene [30]. Similarly, researchers have used a permanent magnet to separate polymer particles suspended in paramagnetic solution [31]. Using a superconducting magnet that generates high gradient fields, the separation was possible without paramagnetic media [21]. Attaching magnetic nanoparticles to target diamagnetic particles greatly facilitates separation of the latter [32]. Magnetic levitation enables separation of organic powders, crystal polymorphisms, and chiral/racemic products [33-35]. Researchers have non-destructively detected defects in plastic parts [36]. Magnetic levitation is also effective for assembling polymer particles [37].

\subsection{Particle Manipulation and Patterning}

A magnetic force also enables control of mass transfer. The magnetic energy $E(x, y, z)$ of a particle suspended in a medium in a magnetic field is expressed by:

$$
E(x, y, z)=-\frac{\chi_{1}-\chi_{2}}{2 \mu_{0}} V B(x, y, z)^{2}+\left(\rho_{1}-\rho_{2}\right) g z
$$

where $B(x, y, z)$ is the magnetic field at the point specified by $(x, y, z)$; the $\left(\rho_{1} \cdot-\rho_{2}.\right) g z$ term is attributable to gravity; $\chi$ is the magnetic susceptibility; $\rho$ is the density; the suffixes 1 and 2 denote the particle and medium, respectively. If one properly combines the parameters in Equation (5) and the distribution of the magnetic field $B(x, y, z)$, a minimum of $E(x, y, z)$ can be generated at a particular three-dimensional position. Then, particles are bound to this minimum. Several methods have been proposed to generate minima [38]. The spacing of the minima can be as narrow as $100 \mu \mathrm{m}$, and micrometer-sized diamagnetic particles can be assembled [39]. By changing the position of the minimum point, researchers can transport the trapped particles.

Figure 4 shows two-dimensional patterns of nanoparticles formed over magnetic minima created by a magnetic modulator consisting of a permalloy that has an array of holes. A glass plate, $130 \mu \mathrm{m}$ thick, is placed on the magnetic modulator, and the particle dispersion is cast on the plate and dried in a magnetic field of $8 \mathrm{~T}$. Because the magnetic flux preferentially passes through the ferromagnetic 
substrate, the magnetic flux density over the holes decreases. As a result, the diamagnetic particles collect over the holes and the paramagnetic particles collect elsewhere. Magnetic trapping is promising for contactless manipulation of microparticles and cells [40-42].

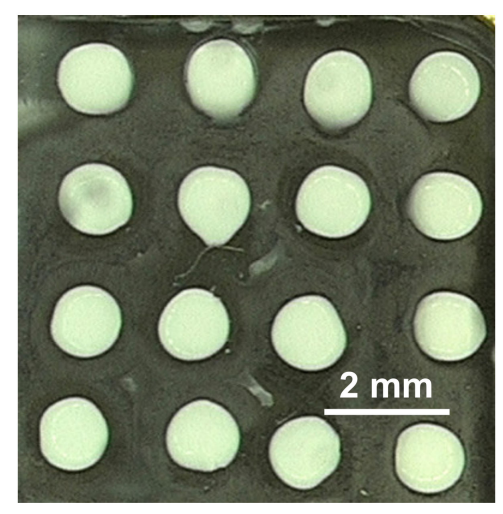

(a)

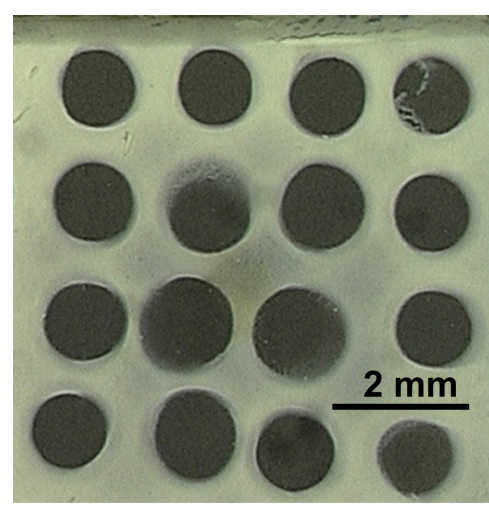

(b)

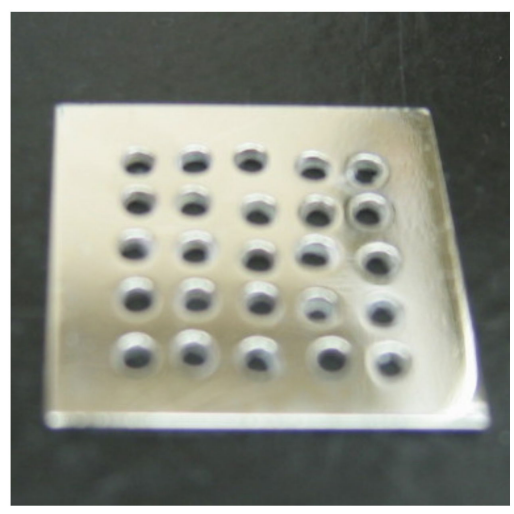

(c)

Figure 4. (a) Patterned polystyrene nanoparticles (sizes of $1.0 \mu \mathrm{m}$, diamagnetic) and (b) patterned polystyrene nanoparticles including Eu (sizes of $260 \mathrm{~nm}$, paramagnetic) formed on a glass plate placed on (c) permalloy substrate with holes. The direction of the applied magnetic field of $8 \mathrm{~T}$ was normal to the substrate.

\subsection{Crystallization Under Levitation}

Researchers often consider magnetic levitation to be an alternative to the microgravity of space, for example, for crystal growth [43-46]. Molecular crystals are often prepared from solutions. Crystals grow in saturated solutions by molecular deposition onto the surface of pre-formed small crystals. The depletion zone forms by molecular deposition near the crystal surface, where the solution density is lower than in the outer region. Thus, the solution in the depletion zone rises by buoyancy and the depletion zone refreshes with fresh saturated solution flowing toward the surface of the growing crystal. This buoyancy convection has various effects on crystal growth. For example, protein concentration around the crystal is disturbed because of this flow, leading to a deteriorated crystal quality [47]. Similarly, disturbing the concentration distribution of impurities such as protein oligomers around the crystal also deteriorates crystal quality [48]. Furthermore, convection promotes deposits and incorporation of dust particles in the solution onto the crystal surface [49]. However, microgravity suppresses convection, resulting in high quality crystal growth [50]. Researchers have also improved protein crystal quality grown under quasi-microgravity by balancing gravity and magnetic force [43-46]. In situ observations of crystal growth under magnetic force-based quasi-microgravity provide insight into crystal growth [51].

\section{Magnetic Torque}

\subsection{Magnetic Anisotropy}

The magnetic anisotropy of a molecule arises from the magnetic anisotropy of its chemical bonds. The magnetic susceptibility of a sigma bond is smaller in the direction parallel to the bond axis $\left(\chi_{\|}\right)$ than in the direction perpendicular to the bond axis $\left(\chi_{\perp}\right)$. In other words, the anisotropic magnetic susceptibility $\chi_{\mathrm{a}}$, defined by $\chi_{\mathrm{a}}=\chi_{\|}-\chi_{\perp}$, is negative. Both $\chi_{\|}$and $\chi_{\perp}$ are negative (diamagnetic). Conversely, $\chi_{a}$, for double bonds such as $\mathrm{C}=\mathrm{C}$ and $\mathrm{C}=\mathrm{O}$, is positive. Aromatic rings have a smaller susceptibility in the direction perpendicular to the ring [52].

Polymeric fibers are elongated in the fiber direction. For example, in polyethylene fibers, the main-chain sigma bonds are elongated in the direction of the fiber axis, and thus, $\chi_{\mathrm{a}}<0$ [53]. Here, 
$\|$ and $\perp$ indicate the directions parallel and perpendicular to the fiber axis, respectively, whereas $\chi_{\mathrm{a}}<0$ for cellulose fibers and nylon fibers, $\chi_{\mathrm{a}}>0$ for carbon fibers [53-55].

In general, the anisotropic magnetic susceptibility of a crystal is expressed by the magnetic susceptibility tensor $\chi$. Its principal values are expressed by $\chi_{1}, \chi_{2}$, and $\chi_{3}$, and the associated principal axes are termed the $\chi_{1}, \chi_{2}$, and $\chi_{3}$ axes. Here, we define $\chi_{1} \geq \chi_{2} \geq \chi_{3}$. For isotropic crystals, $\chi_{1}=\chi_{2}=$ $\chi_{3}$. For uniaxial crystals, including trigonal, tetragonal, and hexagonal, $\chi_{2}$ is equal to either $\chi_{1}$ or $\chi_{3}$, where either $\chi_{1}$ or $\chi_{3}$ is the major axis. For biaxial crystals, including orthorhombic, monoclinic, and triclinic, the three principal values differ. The magnetic $\chi_{1}, \chi_{2}$ and $\chi_{3}$ axes are orthogonal to each other, and they are related to corresponding crystallographic axes [56].

\subsection{Anisotropic Magnetic Energy}

If a particle has magnetic anisotropy, its magnetic energy depends on its orientation relative to the applied magnetic field. This anisotropic magnetic energy causes a torque on the particle. The initial orientation of the particle changes with respect to direction such that the magnetic energy decreases. The particle ends up with the orientation that has a minimum energy. The particle may oscillate before reaching the final orientation depending on the viscosity of the medium suspending the particle. If the viscosity is high enough to overwhelm the inertia term, the rotation of the particle is strongly dampened and oscillation does not occur.

The anisotropic magnetic energy of crystal is expressed by [57]:

$$
E_{\text {mag }}^{\mathrm{a}}=\left(2 \mu_{0}\right)^{-1} B^{2} V\left\{K_{1}\left(\chi_{2}-\chi_{3}\right) \psi^{2}+K_{2}\left(\chi_{1}-\chi_{3}\right) \theta^{2}+K_{3}\left(\chi_{1}-\chi_{2}\right) \phi^{2}\right\}
$$

where $K_{1}, K_{2}$, and $K_{3}$ are constants that depend on which type of magnetic field is applied (e.g., static or rotating). In Equation (6), only the quadratic terms of the Euler angles $[\psi, \theta$, and $\phi$ (Figure 5)] are shown; the isotropic and higher terms are not included. The value of $E_{\text {mag }}^{a}$ reaches a minimum at $\psi=$ $\theta=\phi=0$, indicating that the three magnetic axes are aligned. Near this minimum, the torque-for example, about the $z$-axis-is expressed by $-\partial E_{\text {mag }}^{a} / \partial \phi$.
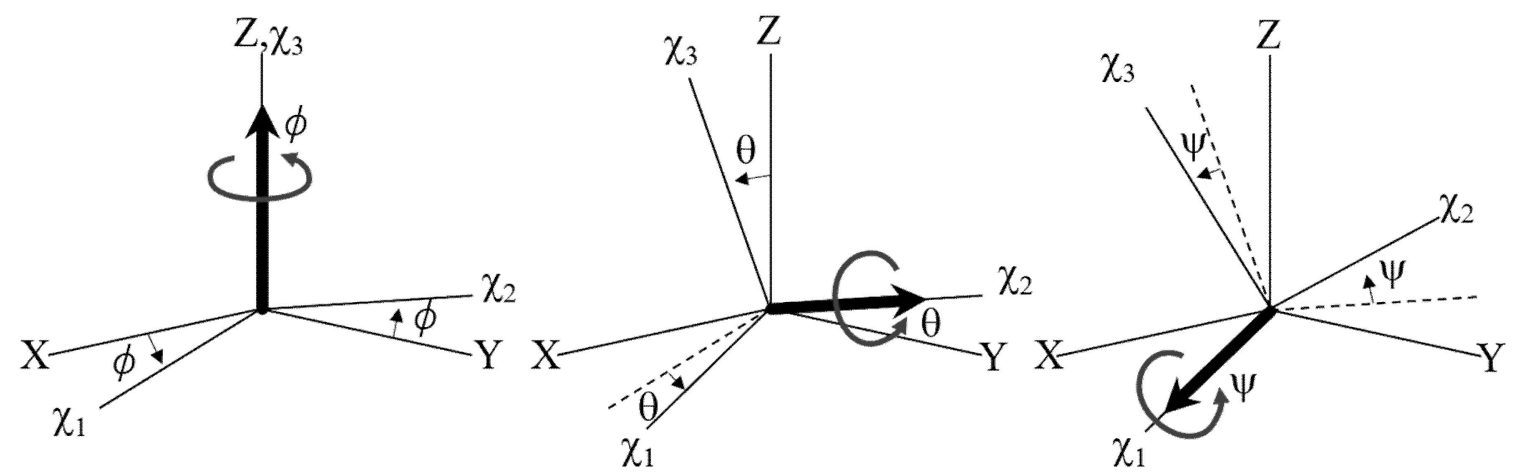

Figure 5. Euler angles $\phi, \theta$, and $\psi$ that define the relationship between the magnetic $\chi_{1}, \chi_{2}$, and $\chi_{3}$ axes and the laboratory coordinates $X, Y$, and Z. $\phi, \theta$, and $\psi$ are consecutive rotations about the $\chi_{3}, \chi_{2}$, and $\chi_{1}$ axes, respectively. When these angles are infinitesimally small, they correspond to the rotation about the laboratory $\mathrm{Z}, \mathrm{Y}$, and $\mathrm{X}$ axes, respectively.

The magnetic $\chi_{1}=\chi_{2}=\chi_{3}$ axes are closely associated with the crystal axes, and therefore, the alignment of the magnetic axes indicates that the crystal is aligned. To achieve alignment of the magnetic axes, specific magnetic fields must be applied. 


\subsection{Magnetic Orientation of Uniaxial Particles}

Consider uniaxial particles such as fibers, whiskers, and uniaxial crystals. The magnetic susceptibility of these particles is defined by $\chi_{\|}$and $\chi_{\perp}$, where $\|$ and $\perp$ indicate the directions parallel and perpendicular to the major magnetic axis, respectively (Figure 6a). The major magnetic axis can be the $\chi_{1}$ or $\chi_{3}$ axis. The anisotropic magnetic energy is expressed by:

$$
E_{\text {static }}(\theta)=-\frac{\chi_{\mathrm{a}} V B^{2}}{2 \mu_{0}} \cos ^{2} \theta
$$

where $\chi_{\mathrm{a}}$ is the anisotropic magnetic susceptibility defined by $\chi_{\mathrm{a}}=\chi_{\|}-\chi_{\perp}$, and $\theta$ is the angle between $B$ and the $\chi_{\|}$axis. If $\chi_{\mathrm{a}}>0$ (i.e., $\chi_{1}=\chi_{\|}>\chi_{\perp}$ ), the magnetic energy reaches a minimum when the $\chi_{\|}$ axis aligns parallel to $B(\theta=0)$ (Figure $6 \mathrm{~b}$ ). As a result, the $\chi_{\|}$axis aligns uniaxially. However, if $\chi_{\mathrm{a}}<0$, (i.e., $\chi_{3}=\chi_{\|}<\chi_{\perp}$ ), the magnetic energy reaches a minimum when the $\chi_{\|}$axis aligns perpendicular to $B$ $(\theta=\pi / 2)$, the $\chi_{\|}$axes assume a planar distribution in the plane perpendicular to $B$.

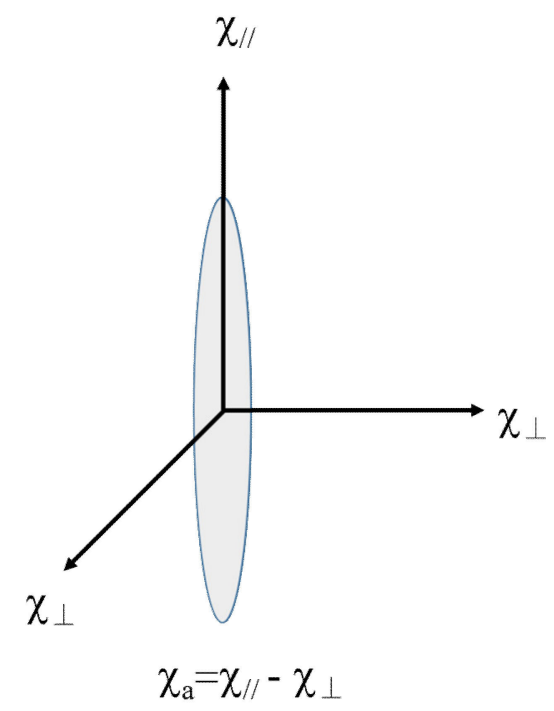

(a)

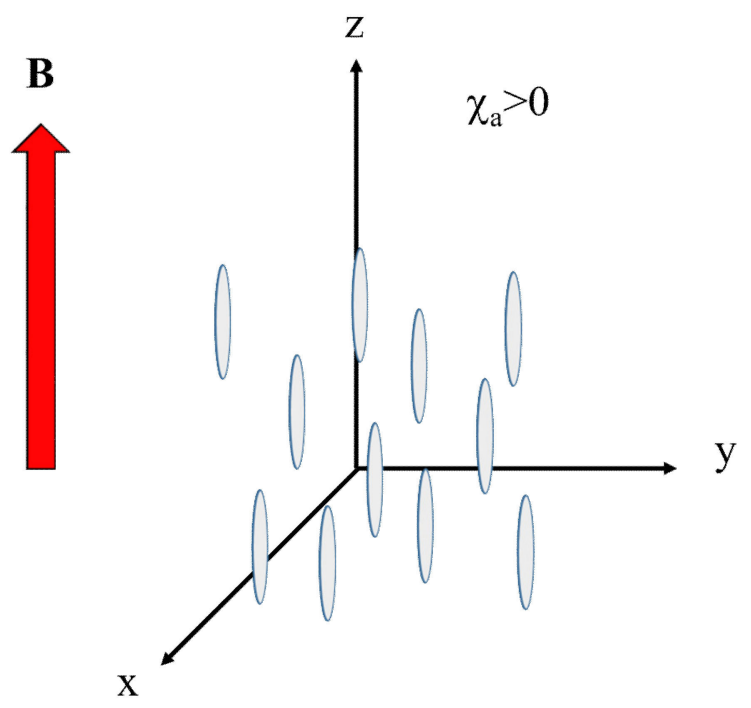

(b)

Figure 6. (a) Principal axes $\chi_{\|}$and $\chi_{\perp}$ of fiber. (b) Schematic drawing of magnetic alignment of fibers with $\chi_{\mathrm{a}}>0$ under static magnetic field.

Fillers are often used in polymer processing. The purpose of adding the filler is to improve physical properties and impart a novel function that is not possessed by the polymer itself. To effectively use the function of the filler, it is important to control the orientation of the filler. However, fillers with shape anisotropy may take undesired orientation during the molding process. Owing to its excellent permeability, a magnetic field is suitable for aligning fillers in a bulk polymer [58-64]. By magnetic orientation of the filler, we can control the anisotropy of the electrical, optical, mechanical and magnetic properties of the composite materials [58,60,61,63]. For example, vertical alignment of fibrous filler such as carbon nanotubes, which is difficult to achieve by common means, is possible not only in bulk composite material but also in thin film composite material [64]. Table 1 summarizes the magnetic alignment of fillers. Some nucleating agents induce epitaxial growth of polymer crystals due to lattice matching. If such a nucleating agent is aligned by a magnetic field, it is possible to align the crystal of polymers [65]. Uniaxial alignment obtained under magnetic fields is also effective as a means to investigate the epitaxy between nucleating agents and polymers because other effects, such as shear, which orients the molecular chain, are negligibly small under magnetic alignment $[66,67]$. 
Table 1. List of magnetically aligned fillers. Orientation direction shows the relationship with a static magnetic field.

\begin{tabular}{cc}
\hline Filler (Shape) & Orientation Direction \\
\hline Carbon Fiber/ Nanotube (fiber) [59,68-70] & Fiber axis $\| B$ \\
Cellulose (fiber) [54,55] & Fiber axis $\perp B$ \\
Graphite/ Graphene (sheet) [71] & Plane-normal $\perp B$ \\
Graphene oxide (sheet) [72,73] & Plane-normal $\perp B$ \\
Hexagonal Boron Nitride (sheet) [74] & Plane-normal $\| B$ \\
Aluminum Nitride (sheet) [75] & Plane-normal $\perp B$ \\
Mica (sheet) [76] & Plane-normal $\perp B$ \\
Montmorillonite(sheet) [77,78] & Plane-normal $\perp B$ \\
Talc (sheet) [79] & Plane-normal $\perp B$ \\
Nontronite (sheet) [80] & Plane-normal $\perp B$ \\
Niobate(V) nanosheet (sheet)[81] & Plane-normal $\perp B$ \\
Titanate(IV) nanosheet (sheet)[81] & Plane-normal $\| B$ \\
Hydroxyapatite (fiber)[82] & Fiber axis $\perp B$ \\
Mordenite zeolite (powder) [83] & Orthorhombic $b$-axis $\| B$ \\
PZT (powder) [84] & Rhombohedral $c$-axis $\perp B$ \\
\hline
\end{tabular}

\subsection{Magnetic Orientation of Biaxial Crystals}

Biaxial alignment of biaxial crystals is possible by using a modulated dynamic magnetic field $[17,85]$. Staines first proposed this idea, which was subsequently developed by Kimura and Yoshino [86,87]. A simple example is described by:

$$
B=\left(B_{x} \cos \omega t, B_{y} \sin \omega t, 0\right)
$$

where $\omega$ is the rotational frequency of the magnetic field. If $B_{x}=B_{y}$, the magnetic field is simply a uniform rotation, as described previously. Under the condition $B_{x}>B_{y}$ and with a sufficiently large $\omega$, the $\chi_{1}$ and $\chi_{3}$ axes align in the $x$ and $z$ directions, respectively. Thus, the three magnetic susceptibility axes are fixed biaxially $[87,88]$. Because these axes are embedded in a unit cell, the biaxial orientation of these axes indicates biaxial alignment of the crystallographic axes. For uniaxial crystals, where $\chi_{2}=\chi_{1}$ or $\chi_{3}$, only the uniaxial alignment of the major axis is achieved.

Uniaxial crystals align uniaxially at a maximum regardless of the type of the applied magnetic field because of the uniaxial magnetic nature of these crystals. However, for biaxial crystals (triclinic, monoclinic, or orthorhombic), a much higher alignment, such as biaxial alignment, is possible. The aforementioned amplitude modulation elliptic field (Equation (8)) is one of these choices. Researchers have also proposed methods such as a frequency-modulated elliptic field, intermittently rotating field, and oscillating field [87-90]. When performing biaxial orientation by means of a modulated magnetic field, the frequency $\omega$ should be sufficiently high.

Researchers use the biaxial technique for fabricating so called pseudo-single crystals, in turn used to perform single-crystal X-ray and single-crystal solid-state nuclear magnetic resonance analyses from powder samples [91,92]. Researchers also use the biaxial technique to analyze the epitaxial mechanism of polymer crystallization on nucleating agents [93]. Recently, researchers developed an instrument that can generate a linear time-modulated magnetic field for continuously producing biaxial alignment [94].

\subsection{Alignment Kinetics}

If $\chi_{\|} \| \chi_{3}$, the $\chi_{\|}$axes assume a planer distribution in the plane that is perpendicular to a magnetic field (Figure 7a). To achieve uniaxial alignment of the $\chi_{\|}$axis, one must use a magnetic field expressed 
by $B=B(\cos \omega t, \sin \omega t, 0)$ rotating in the $x y$-plane at a rotation frequency $\omega$ (Figure $7 \mathrm{~b})$. Under this condition, the time-averaged anisotropic magnetic energy is expressed by:

$$
E_{\text {rotating }}(\theta)=-\frac{\chi_{\mathrm{a}} V B^{2}}{4 \mu_{0}} \cos ^{2} \theta
$$

where $\theta$ is the angle between the z-axis and $\chi_{\|}$axis. The magnetic energy is half that of the static case because the effective power of $B$ is reduced by $\sqrt{2}$ when the magnetic field is rotating.

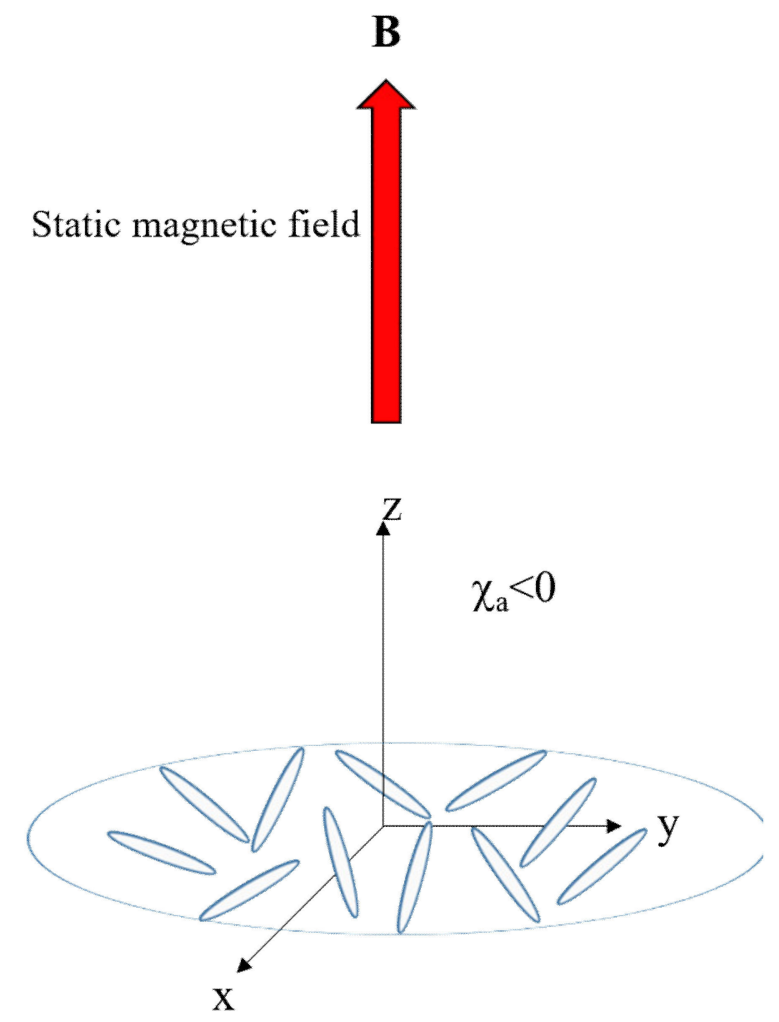

(a)

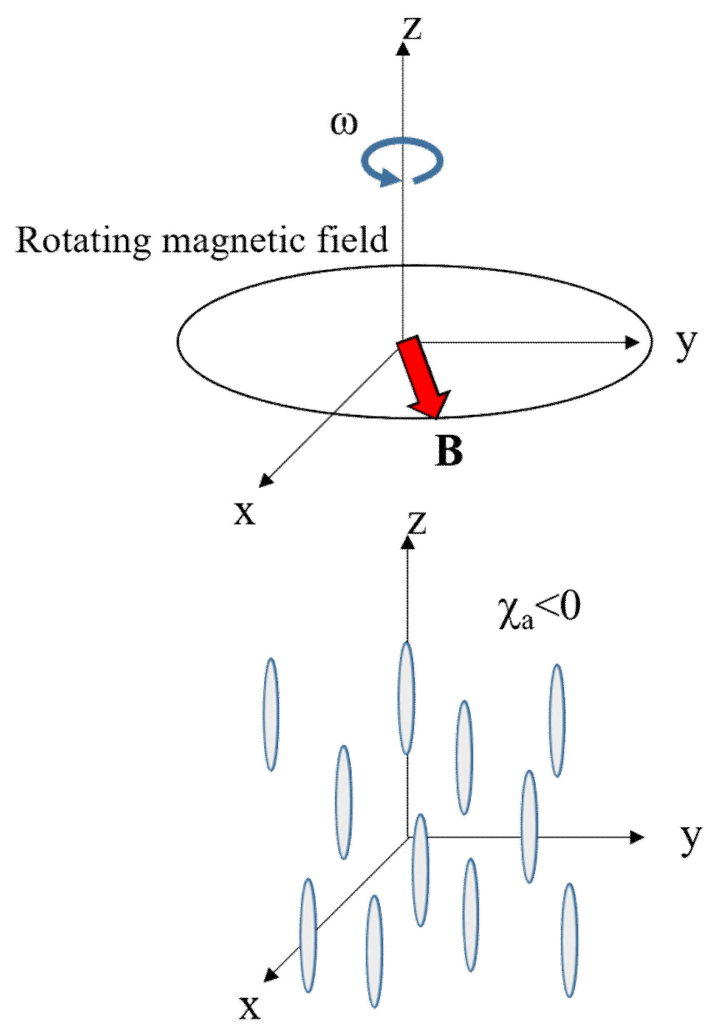

(b)

Figure 7. Schematic drawing of applying magnetic fields and expected alignments of the fiber with $\chi_{\mathrm{a}}<0$. (a) Static magnetic field and (b) rotating magnetic field.

Consider the orientation kinetics of a uniaxial particle subjected to a static magnetic field. Suppose a particle with a magnetic anisotropy $\chi_{a}$ is suspended in a medium with viscosity $\eta$ and subjected to a magnetic field $B$. The balance of the magnetic and hydrodynamic torques describes the particle's rotational motion. Ignoring the inertia term, the equation of motion is expressed by $[95,96]$ :

$$
L \frac{d \theta}{d t}=-\frac{\chi_{\mathrm{a}} V B^{2}}{2 \mu_{0}} \sin 2 \theta
$$

where $\theta$ is the angle between the magnetic field $B$ and the major axis, and $L$ is the hydrodynamic resistance. The solution to Equation (10) is given by

$$
\tan \theta=\tan \theta_{0} \exp (-t / \tau)
$$


where the alignment rate $\tau^{-1}$ is defined by $\tau^{-1}=\left|\chi_{\mathrm{a}}\right| V B^{2} /\left(L \mu_{0}\right)$ [53]. For of a sphere with radius $a, \mathrm{~L}=$ $8 \pi \eta a^{3}$ and $V=4 \pi a^{3} / 3$; thus,

$$
\tau^{-1}=\frac{\left|\chi_{\mathrm{a}}\right| B^{2}}{6 \eta \mu_{0}}
$$

Regarding Equation (12), the alignment rate does not depend on the volume of the particle. This is valid when the particle size is sufficiently large such that Brownian motion can be ignored [17,97]. In a rotating magnetic field, $\tau^{-1}$ is halved because the effective magnetic field is reduced by $\sqrt{2}$ as a consequence of rotation. Figure 8 shows the relationship between $\tau^{-1}$ and $B$ estimated using Equation (12), where we assume the anisotropic diamagnetic susceptibility is $\chi_{\mathrm{a}}=10^{-6}$. Magnetic alignment is very fast in a low-viscosity environment such as water.

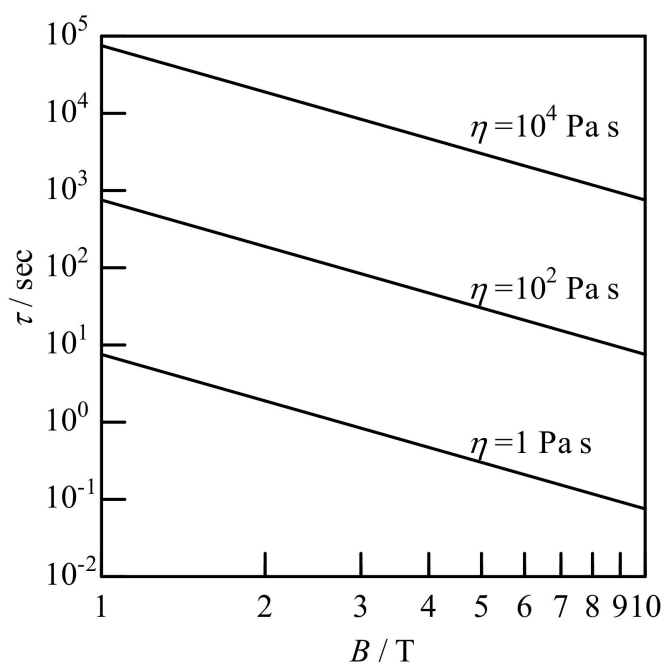

Figure 8. Alignment rate $\tau$ as a function of magnetic flux density $B$ under anisotropic diamagnetic susceptibility of $\left|\chi_{\mathrm{a}}\right|=10^{-6}$. Viscosity of media is shown in the figure.

\section{Magnetic Dipole-Dipole Interaction}

Materials in a magnetic field are magnetized and form magnetic dipoles. The dipole-dipole interaction $E_{12}$ between two magnetic dipoles, $\mu_{1}$ and $\mu_{2}$, is expressed by Equation (13).

$$
E_{12}=-\left(\frac{\mu_{0}}{4 \pi}\right)\left(\frac{3\left(\mu_{1} \cdot r\right)\left(\mu_{2} \cdot r\right)}{r^{5}}-\frac{\left(\mu_{1} \cdot \mu_{2}\right)}{r^{3}}\right)
$$

where $r$ is a distance between the dipoles.

The force acting between the dipoles may be attractive or repulsive, depending on their mutual location and orientation (Figure 9), resulting in aggregates. The force that is attributable to the diamagnetic dipole moments is extremely small and researchers report only a few examples [98-101].

The dipole interaction between ferromagnetic dipoles, however, is very intense. Ferromagnetic particles dispersed in a polymer matrix can be assembled and aligned into a column and/or chain structure by an external magnetic field. The alignment brings about anisotropy in conductivity, magnetic susceptibility, thermal conductivity, permittivity, magnetoresistance, and piezoresistivity [102-109]. Particles form aligned chains from a dilute isotropic system by coagulation, which leads to a conductivity jump and increased transparency in the alignment direction $[110,111]$. The column structure influences the chain orientation of the matrix polymer, resulting in a change in the physical properties of the composite material [112]. The column structure and the structure change in the matrix polymer both affect the physical properties of the composite materials. Researchers also use dipole-dipole interactions to control physical properties by applying magnetic fields. A typical example is magnetic fluid that is a liquid in which ferromagnetic nanoparticles are highly dispersed [113-115]. Applying 
a magnetic field enhances the interactions between the particles in the fluid, thereby increasing the viscosity. The magnetic fluid retained in a gap by a magnetic force acts as a liquid O-ring. Thus, magnetic fluids can be used as a seal [116].

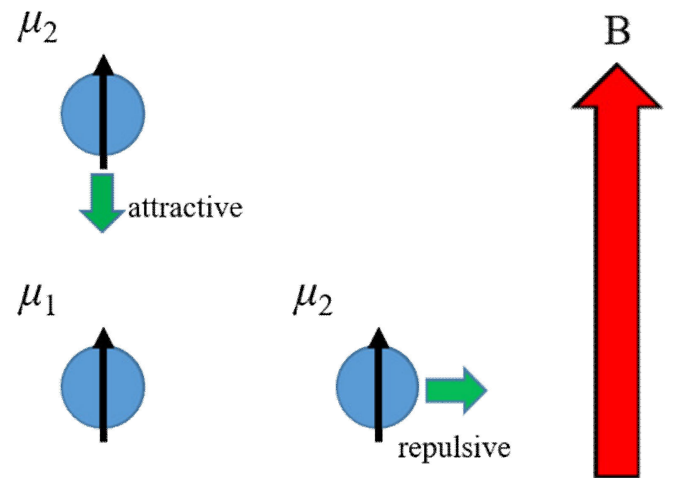

(a)

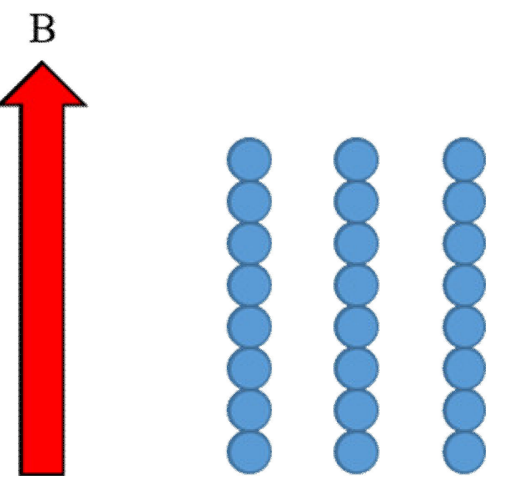

(b)

Figure 9. Dipole-dipole interaction acts on the adjacent magnetic dipoles. (a) Depending on the arrangement between the dipoles, the direction of the force is different. (b) The column structure is formed under a magnetic field.

Researchers reported a magnetic composite material, in which magnetic fine particles are dispersed in a hydrogel [16]. This is an example of a stimuli-responsive functional material. The elastic modulus of this material increases by $500 \times$ in response to the magnetic field.

\section{Thermodynamics: Phase Transition Temperature}

In ferromagnetic materials, one can modulate the phase transition temperature by applying a magnetic field [117]. However, it is difficult to observe this effect for diamagnetic materials because the magnetic energy received by diamagnetic materials is extremely small. There are several studies regarding thermal analysis of organic compounds in a strong magnetic field $[118,119]$. The transition temperatures shifted to higher temperatures by several tens of millikelvin by applying a field of $5 \mathrm{~T}$.

The Magneto-Clapeyron equation expresses the value of the temperature shift that is attributable to the magnetic field [120]:

$$
\Delta T=\frac{\left\{\left(\cos ^{2} \theta-1 / 3\right) \chi_{\mathrm{a}}+\left\langle\chi_{s}\right\rangle-\chi_{l}\right\} B^{2}}{2 \mu_{0} \Delta \bar{H}} T_{m},
$$

where $\Delta \bar{H}$ is the molar transition enthalpy; $\chi_{\mathrm{a}}=\chi_{\|}-\chi_{\perp}$ is as defined previously, $\left\langle\chi_{s}\right\rangle=\left(2 \chi_{\perp}+\chi_{\|}\right) / 3$; $\chi_{1}$ is the magnetic susceptibility of liquid; $T_{\mathrm{m}}$ is the melting temperature in the absence of the magnetic field; $\left\langle\chi_{s}\right\rangle$ is the average of the phase transition temperature in the absence of the magnetic field; $\theta$ is the angle between the applied magnetic field and easy axis (here, we assume $\chi_{\|}$is easy axis). In accordance with Equation (14), the melting point shifts to a higher temperature when the easy axis of magnetization is aligned parallel to the magnetic field (Figure 10). However, the estimated $\Delta T$ is on the order of millikelvins, even if $\Delta \bar{H}$ for the isotropic-anisotropic transition for the liquid-crystal is assumed [120]. $\Delta T$ is much less if $\Delta \bar{H}$ for the melting crystals is assumed. For crystals and liquid-crystal systems $\Delta \bar{H}$, is sufficiently large that it is difficult to observe considerable values of $\Delta T$. Researchers studied the magnetic field effect on the order-disorder transition of a diblock copolymer using in situ $X$-ray scattering, but did not detect a considerable $\Delta T$ [121]. However, researchers reported a larger $\Delta T$ for another order-disorder transition [122]. Recently, researchers reported that the crystallization temperature of polyethylene and polyethylene glycol increases by several degrees in a magnetic field [123]. Likely, a high $\Delta T$ strongly depends on the $\Delta \bar{H}$ of the system under investigation. 


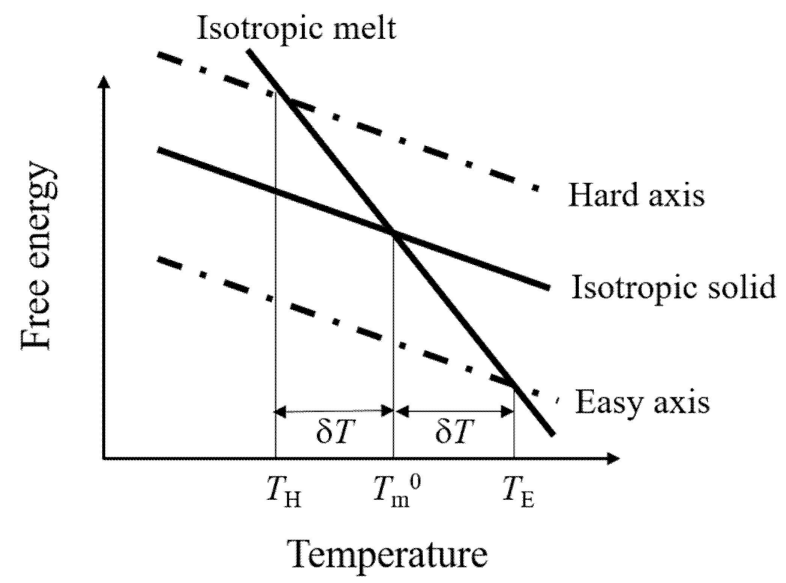

Figure 10. Temperature dependence of free energy. In anisotropic solids, free energy in a magnetic field differs depending on the orientation direction, leading to the orientation dependent shifts of melting point.

\section{Magnetic Orientation of Crystalline Polymers}

Crystalline polymers undergo orientation during crystallization from the molten state in the presence of high magnetic fields. Table 2 shows polymers that researchers have to date reported to align [124-133]. Atactic polymers do not undergo magnetic orientation because they lack an ability to form anisotropic ordered structures. Incidentally, fibers consisting of atactic polymers can align because the elongated chains exhibit magnetic anisotropy in the direction of the fiber axis. Both aromatic and aliphatic polymers undergo magnetic orientation, indicating that the intensity of the magnetic anisotropy of the constituent monomers is less important. Three factors determine the alignment-the magnetic anisotropy of the monomer, the secondary structures of the polymer chain, and packing in the crystal. All of these factors contribute to the magnetic anisotropy of the crystal.

Figure 11 shows a typical thermal history used to obtain magnetic orientation. We maintained a polymer sample in a magnetic field, at a temperature between the melting temperature $\left(T_{\mathrm{m}}\right)$ determined by differential scanning calorimetry and the equilibrium melting temperature $\left(T_{\mathrm{m}}{ }^{0}\right)$. Then, we subjected the sample to isothermal crystallization in the magnetic field at a temperature below $T_{\mathrm{m}}$. The polymer chain orientation can easily occur by shearing strain, temperature gradient, etc. Therefore, these factors should be carefully removed so that the magnetic effect on orientation can clearly observed.

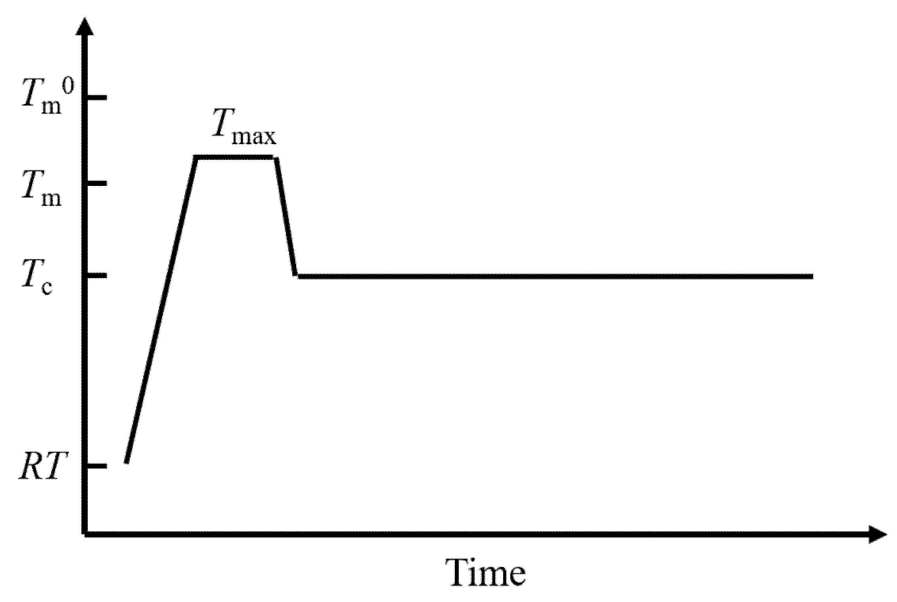

Figure 11. Typical thermal history necessary for the magnetic alignment of crystalline polymers. $T_{\mathrm{m}}{ }^{0}$-equivalent melting point; $T_{\mathrm{m}}$-melting point; $T_{\max }$-melting temperature; $T_{\mathrm{C}}$-crystallization temperature. 
The mechanism of the magnetic orientation of polymeric materials is complicated compared with that of solid particles suspended in a liquid medium, because the magnetic process is coupled with the crystallization process. Furthermore, polymer crystallization itself remains contentious; researchers have proposed various crystallization mechanisms [134].

Two models for the orientation mechanism are as follows. The rotation model is a simple analogue to the magnetic orientation of solid particles in suspension. This model assumes that some ordered anisotropic structures rotate because of the magnetic torque. Here, the ordered anisotropic structures are not limited to crystals but may be, for example, mesophases, liquid-crystalline phases, conformationally disordered phases, crystal embryos, or microcrystals, formed at an early stage of crystallization when the viscosity is not yet substantially high.

In the preference-growth model, the ordered anisotropic structure that happens to have $\chi_{1}$-axis (easy axis) alignment has a melting temperature that is higher by $\Delta T$ compared with the isotropic structure, in accordance with the aforementioned Magneto-Clapeyron equation. Thus, under supercooling, the $\chi_{1}$-axis-aligned structure has higher supercooling compared with the isotropic structure, resulting in preferential structure formation. As discussed previously, $\Delta T$ might be very small for the crystalline phase, yet large for mesophases because of its small $\Delta H$.

In situ birefringence measurement of a polymer melt undergoing crystallization shows birefringence that can be seen at an early stage of crystallization, where the crystals detectable by X-ray diffraction were not yet formed [129]. The origin of the birefringence is attributable to the oriented anisotropic structures that are not the crystal.

Researchers have investigated the origin of anisotropic structures [135]. The orientation degree and crystal texture largely depended on the temperature $T_{\max }$ (Figure 11) to which the specimen was exposed before being subjected to isothermal crystallization. Researchers achieved higher alignments when the specimen was treated at lower $T_{\max }$ values. Upon treatment at a high $T_{\max }$, researchers obtained only a small number of large spherulites, without orientation. Similar observations have been reported elsewhere [130]. Magnetic orientation competes with spherulite formation. However, upon treatment at a low $T_{\max }$, the sample exhibited a large number of small and oriented crystallites.

Table 2. List of magnetically aligned crystalline polymers during melt crystallization. Orientation direction shows the relationship with a static magnetic field.

\begin{tabular}{cc}
\hline Polymer (Crystal System) & Orientation Direction \\
\hline Polyethene-2,6-naphthalate (triclinic) [136] & $c$-axis $\| B$ (approximately) \\
Bisphenol A Polycarbonate (orthorhombic) [125] & $c$-axis $\| B$ \\
Polyethylene terephthalate (triclinic) [126] & $c$-axis $\perp B$ (approximately) \\
Polyethylene (orthorhombic) [127] & $c$-axis $\perp B$ \\
Isotactic Polypropylene (monoclinic) [128] & $c$-axis $\perp B$ \\
Isotactic Polystyrene (hexagonal) [129,130] & $c$-axis $\perp B$ \\
Syndiotactic Polystyrene (orthorhombic) [131] & $c$-axis $\perp B$ \\
Nylon 6 (monoclinic) [132] & $c$-axis $\perp B$ \\
Poly-L-lactide (orthorhombic) [133] & $c$-axis $\perp B$ \\
\hline
\end{tabular}

These observations suggest that the origin of the anisotropic structure is related to residual microcrystals that remain even above $T_{\mathrm{m}}$. Usually, researchers heat the sample from room temperature, and the sample undergoes cold crystallization. As a result, the sample contains a number of microcrystals before it reaches $T_{\mathrm{m}}$. Of course, the remaining microcrystals assumed here cannot be in a form of crystal detectable by X-ray diffraction, but they may be in a form of partially molten disordered crystals, which may be called, for example, mesophase or liquid crystalline phase. Researchers do not yet know whether these structures are stable in equilibrium or only kinetically. If the heat treatment temperature $T_{\max }$ is higher than the equilibrium melting temperature $\left(T_{\mathrm{m}}{ }^{0}\right)$, the residual structure no longer remains and there is no magnetic orientation. Commercially available crystalline polymers 
including poly(ethylene terephthalate), poly(ethylene), nylon, and poly(propylene) undergo magnetic orientation during crystallization from melts (Table 2).

\section{Magnetic Orientation of Microphase-Separated Structure}

Researchers use nanoscale structures formed by microphase separation of block copolymers as templates for developing functional materials [137]. Magnetic alignment also occurs in microphase separation of block copolymers. Researchers can use magnetic alignment to obtain a uniform alignment over a large area.

As mentioned previously, crystalline polymers undergo magnetic alignments. The crystalline and liquid-crystalline blocks of block copolymers exhibit magnetic orientation [138,139]. Researchers have reported magnetic orientation of nanoscale structures with cylindrical and lamellar morphology [140-148]. The liquid-crystalline block does not necessarily ensure magnetic orientation of nanostructures [142]. Even if the block copolymer contains an anisotropic component such as a liquid-crystalline and crystalline block, a magnetic anisotropy energy that is greater than the thermal energy and a low viscosity environment that is rotatable by magnetic torque are necessary for magnetic orientation of nanoscale structures.

Osuji and colleagues successfully magnetically aligned a microphase-separated structure formed by a block copolymer consisting of amorphous polymers [149]. Generally, the chains of amorphous polymers form a random coil, resulting in an isotropic structure. It is not immediately obvious why anisotropic polymers can undergo magnetic alignment. An explanation may be molecular orientation at the interface of the microphase-separated structure, or Magneto-Clapeyron type effect occurring with small transition enthalpy.

\section{Conclusions}

We reviewed magnetic phenomena of diamagnetic materials, focusing mainly on polymeric materials. Phenomena such as magnetic levitation, separation, and manipulation of particles originate from the magnetic force, whereas phenomena such as orientation (e.g., crystals and fibers) originate from the magnetic torque. Both the force and torque derive from well-defined magnetic energy. Hence, the phenomena caused by these factors are clearly understood. For example, the magnetic orientation of fillers in polymeric materials is clearly attributable to the action of the magnetic torque on the filler.

The magnetic energy comes into play as an enthalpy term in the free energy when materials are undergoing a phase transition. Crystalline polymers undergo magnetic orientation during crystallization from melts. Additionally, microstructures of block copolymers align under a magnetic field. The alignment mechanism in these systems may be described by preference-growth or rotation of the ordered structure. It is sometimes difficult to determine which factor is dominant because of researchers' imperfect knowledge of the phase transition of these systems.

Strong magnetic fields are surely optimal compared with weak magnetic fields for maximizing the magnetic effect. Recently, strong magnetic fields such as $10 \mathrm{~T}$ or more have become readily accessible to materials scientists and engineers. Although they are not very strong, neodymium magnets of approximately $1 \mathrm{~T}$ are much more readily accessible and useful for magnetic processing in many cases. A magnetic field of these strengths is as powerful as an electric field for particle alignment, and superior to electric fields in terms of penetrability.

In addition to the intensity, special and temporal modulations of magnetic field are promising for expanding the potential of magnetic fields for processing. With special modulation ranging from macroscale to microscopic orders, various force fields can be created. With temporal modulation, precise three-dimensional alignment of microcrystals is possible, which will be useful for materials science as well as X-ray diffraction, neutron diffraction, and solid-state nuclear magnetic resonance analyses of microcrystalline powders.

The future prospects of magnetic applications can be summarized as follows: 
Intensity-Compared with weaker magnetic field strengths, stronger magnetic field strengths are better. However, users must wait for the development of superconducting technology. The stronger the magnetic field, the smaller the available space. Currently, 10T/100 $\mathrm{mm} \varphi$ and 5T/400 $\mathrm{mm} \varphi$ are commercially available. A pulsed magnetic field is one option when high intensity is required and duration can be sacrificed somewhat. It is necessary to devise an approach to utilize the magnetic field under such restrictions.

A strong magnetic field is advantageous for orientation, especially when the oriented samples are to be subjected to single-crystal analyses by $\mathrm{X}$-ray diffraction, neutron diffraction, and nuclear magnetic resonance. However, for micrometer-scale particles, weaker magnetic fields such as those supplied by a neodymium magnet $(\sim 1 \mathrm{~T})$ are sufficient for alignment, indicating widespread applications in materials science.

Spatial modulation—Regarding separation, the magnetic force $(\sim \triangle \chi B d B / d z)$ plays an important role. In such circumstances, a weak $B$ is sufficient to create a large magnetic force if a large magnetic field gradient $d B / d z$ is produced. Because of the divergent nature of magnetic fields, a weak $d B / d z$ is ubiquitous. A spatially modulated magnetic field, produced over a microscopically designed bumpy surface of a ferromagnetic material placed in a magnetic field, might be useful for microscopically patterning microparticles and nanoparticles. If one immerses diamagnetic particles in a ferromagnetic or paramagnetic fluid, the difference $\Delta \chi$ between the particle and medium is substantial, resulting in a large magnetic force. Micropatterning can be applied to a wide range of microparticles, ranging from ceramics to cells. A limitation of this technique is that the field modulation persists only over a very short distance-proportional to the pitch of the bumps on the ferromagnetic surface.

Temporal modulation-A time-dependent magnetic field (TDMF) is a promising means to expand the utility of magnetic fields. Three-dimensional alignment of microcrystals is an example. More fundamentally, from the Maxwell equation, $\operatorname{rot} E=-\partial B / \partial t$, the TDMF essentially induces the electric field $E$. Therefore, the phenomena observed under TDMF are a result of simultaneous application of magnetic and electric fields. The magnitude of $E$ is proportional to the frequency $\omega$ of $B$; thus, $E$ may be large if $\omega$ is as high as the frequency of light. The potential of TDMF seems unexplored currently.

Effect on phase transition-In accordance with the Magneto-Clapeyron equation, the shift of the transition temperature $\Delta T$ is inversely proportional to the transition enthalpy $\Delta H$. This indicates that a very weak first-order phase transition may be very susceptible to the applied magnetic field. Phase separation of block copolymers, phase changes of surfactant solutions, and structure formation during the incubation period of crystallization may fall into the category of weak first-order phase transitions. At present, few studies have focused on these aspects of the magnetic effect.

Author Contributions: Writing—review and editing, M.Y. and T.K.; visualization, M.Y. All authors have read and agreed to the published version of the manuscript.

Funding: This research received no external funding.

Acknowledgments: We thank Edanz Group (https://en-author-services.edanzgroup.com) for editing a draft of this manuscript.

Conflicts of Interest: The authors declare no conflict of interest.

\section{References}

1. Van Vleck, J.H. The Classical Theory of Magnetic Susceptibilities. In The Theory of Electric and Magnetic Susceptibilities; Oxford University Press: London, UK, 1932; pp. 91-94.

2. Wagner, D. Diamagnetism. In Introduction to the Theory of Magnetism; Pergamon Press: Oxford, UK, 1972; pp. 6-8.

3. Gupta, R.R. Semiempirical calculation of diamagnetic susceptibilities of organo-silicon compounds containing carbon-silicon bonds. J. Chem. Phys. 1977, 67, 3298-3299. [CrossRef] 
4. Maret, G.; Schickfus, M.v.; Mayer, A.; Dransfeld, K. Orientation of Nucleic Acids in High Magnetic Fields. Phys. Rev. Lett. 1975, 35, 397-400. [CrossRef]

5. Beaugnon, E.; Tournier, R. Levitation of organic materials. Nature 1991, 349, 470. [CrossRef]

6. Motokawa, M.; Hamai, M.; Sato, T.; Mogi, I.; Awaji, S.; Watanabe, K.; Kitamura, N.; Makihara, M. Magnetic levitation experiments in Tohoku University. Phys. B Condens. Matter 2001, 294-295, 729-735. [CrossRef]

7. Simon, M.D.; Geim, A.K. Diamagnetic levitation: Flying frogs and floating magnets (invited). J. Appl. Phys. 2000, 87, 6200-6204. [CrossRef]

8. Hirota, N.; Homma, T.; Sugawara, H.; Kitazawa, K.; Iwasaka, M.; Ueno, S.; Yokoi, H.; Kakudate, Y.; Fujiwara, S.; Kawamura, M. Rise and fall of surface level of water solutions under high magnetic field. Jpn. J. Appl. Phys. Part 2 Lett. 1995, 34, L991-L993. [CrossRef]

9. Yamaguchi, M.; Tanimoto, Y. (Eds.) Magneto-Science: Magnetic Field Effects on Materials: Fundamentals and Applications; Springer: Berlin/Heidelberg, Germany, 2006.

10. Hayashi, H. Introduction to Dynamic Spin Chemistry Magnetic Field Effects of Chemical and Biochemical Reactions; World Scientific Publishing Co.Pte. Ltd: Singapore, 2004; ISBN 9812384235.

11. Sakaguchi, A.; Hamasaki, A.; Ozeki, S. Colloid and Interface Chemistry under Magnetic Fields. Chem. Lett. 2012, 41, 342-348. [CrossRef]

12. Shoogo, U.; Masaki, S. (Eds.) Biomagnetics: Principles and Applications of Biomagnetic Stimulation and Imaging; CRC Press: Boca Raton, FL, USA, 2016.

13. Kimura, T. Study on the effect of magnetic fields on polymeric materials and its application. Polym. J. (Tokyo, Japan) 2003, 35, 823-843. [CrossRef]

14. Hu, H.; Gopinadhan, M.; Osuji, C.O. Directed self-assembly of block copolymers: A tutorial review of strategies for enabling nanotechnology with soft matter. Soft Matter 2014, 10, 3867. [CrossRef]

15. Kimura, T. Magnetic Processing of Feeble Magnetic Materials under High Magnetic Fields. Magn. Jpn. 2009, 4, 516-523. (In Japaneas)

16. Mitsumata, T.; Honda, A.; Kanazawa, H.; Kawai, M. Magnetically Tunable Elasticity for Magnetic Hydrogels Consisting of Carrageenan and Carbonyl Iron Particles. J. Phys. Chem. B 2012, 116, 12341-12348. [CrossRef] [PubMed]

17. Yamaguchi, M.; Ozawa, S.; Yamamoto, I. Rotational Diffusion Model of Magnetic Alignment. Jpn. J. Appl. Phys. 2009, 48, 063001. [CrossRef]

18. Motokawa, M. Magnetic Levitation. In Materials Science in Static High Magnetic Fields; Watanabe, K., Motokawa, M., Eds.; Springer-Verlag: Berlin/Heidelberg, Germany, 2002; pp. 263-282.

19. Ge, S.; Semenov, S.N.; Nagarkar, A.A.; Milette, J.; Christodouleas, D.C.; Yuan, L.; Whitesides, G.M. Magnetic Levitation To Characterize the Kinetics of Free-Radical Polymerization. J. Am. Chem. Soc. 2017, 139, 18688-18697. [CrossRef] [PubMed]

20. Ilievski, F.; Mirica, K.A.; Ellerbee, A.K.; Whitesides, G.M. Templated self-assembly in three dimensions using magnetic levitation. Soft Matter 2011, 7, 9113. [CrossRef]

21. Tanimoto, Y.; Fujiwara, M.; Sueda, M.; Inoue, K.; Akita, M. Magnetic Levitation of Plastic Chips: Applications for Magnetic Susceptibility Measurement and Magnetic Separation. Jpn. J. Appl. Phys. 2005, 44, 6801-6803. [CrossRef]

22. Berry, M.V.; Geim, A.K. Of flying frogs and levitrons. Eur. J. Phys. 1997, 18, 307-313. [CrossRef]

23. Catherall, A.T.; Eaves, L.; King, P.J.; Booth, S.R. Floating gold in cryogenic oxygen. Nature 2003, $422,579$. [CrossRef]

24. Ikezoe, Y.; Hirota, N.; Nakagawa, J.; Kitazawa, K. Making water levitate. Nature 1998, 393, 749-750. [CrossRef]

25. Ikezoe, Y.; Kaihatsu, T.; Uetake, H.; Hirota, N.; Nakagawa, J.; Kitazawa, K. Stable levitation of water by magneto-Archimedes principle. Trans. Mater. Res. Soc. Japan 2000, 25, 77-80.

26. Mirica, K.A.; Phillips, S.T.; Mace, C.R.; Whitesides, G.M. Magnetic Levitation in the Analysis of Foods and Water. J. Agric. Food Chem. 2010, 58, 6565-6569. [CrossRef]

27. Kitamura, N.; Makihara, M.; Hamai, M.; Sato, T.; Mogi, I.; Awaji, S.; Watanabe, K.; Motokawa, M. Containerless Melting of Glass by Magnetic Levitation Method. Jpn. J. Appl. Phys. 2000, 39, L324-L326. [CrossRef]

28. Yamato, M.; Nakazawa, H.; Kimura, T. Levitation Polymerization to Fabricate a Large Polymer Sphere. Langmuir 2002, 18, 9609-9610. [CrossRef]

29. Kimura, T.; Mamada, S.; Yamato, M. Separation of Solid Polymers by Magneto-Archimedes Levitation. Chem. Lett. 2000, 29, 1294-1295. [CrossRef] 
30. Ueda, Y.; Mishima, F.; Akiyama, Y.; Nishijima, S. Fundamental Study of Plastic Separation Utilizing Magnetic Force. IEEE Trans. Appl. Supercond. 2014, 24, 1-5. [CrossRef]

31. Winkleman, A.; Perez-Castillejos, R.; Gudiksen, K.L.; Phillips, S.T.; Prentiss, M.; Whitesides, G.M. Density-based diamagnetic separation: Devices for detecting binding events and for collecting unlabeled diamagnetic particles in paramagnetic solutions. Anal. Chem. 2007, 79, 6542-6550. [CrossRef] [PubMed]

32. Iranmanesh, M.; Hulliger, J. Magnetic separation: Its application in mining, waste purification, medicine, biochemistry and chemistry. Chem. Soc. Rev. 2017, 46, 5925-5934. [CrossRef] [PubMed]

33. Maki, S.; Hirota, N. Magnetic separation technique on binary mixtures of sorbitol and sucrose. J. Food Eng. 2014, 120, 31-36. [CrossRef]

34. Atkinson, M.B.J.; Bwambok, D.K.; Chen, J.; Chopade, P.D.; Thuo, M.M.; Mace, C.R.; Mirica, K.A.; Kumar, A.A.; Myerson, A.S.; Whitesides, G.M. Using Magnetic Levitation to Separate Mixtures of Crystal Polymorphs. Angew. Chemie Int. Ed. 2013, 52, 10208-10211. [CrossRef]

35. Yang, X.; Wong, S.Y.; Bwambok, D.K.; Atkinson, M.B.J.; Zhang, X.; Whitesides, G.M.; Myerson, A.S. Separation and enrichment of enantiopure from racemic compounds using magnetic levitation. Chem. Commun. 2014, 50, 7548-7551. [CrossRef]

36. Hennek, J.W.; Nemiroski, A.; Subramaniam, A.B.; Bwambok, D.K.; Yang, D.; Harburg, D.V.; Tricard, S.; Ellerbee, A.K.; Whitesides, G.M. Using Magnetic Levitation for Non-Destructive Quality Control of Plastic Parts. Adv. Mater. 2015, 27, 1587-1592. [CrossRef]

37. Mirica, K.A.; Ilievski, F.; Ellerbee, A.K.; Shevkoplyas, S.S.; Whitesides, G.M. Using Magnetic Levitation for Three Dimensional Self-Assembly. Adv. Mater. 2011, 23, 4134-4140. [CrossRef] [PubMed]

38. Ge, S.; Whitesides, G.M. "Axial” Magnetic Levitation Using Ring Magnets Enables Simple Density-Based Analysis, Separation, and Manipulation. Anal. Chem. 2018, 90, 12239-12245. [CrossRef] [PubMed]

39. Kimura, T.; Yamato, M.; Nara, A. Particle Trapping and Undulation of a Liquid Surface Using a Microscopically Modulated Magnetic Field. Langmuir 2004, 20, 572-574. [CrossRef] [PubMed]

40. Subramaniam, A.B.; Yang, D.; Yu, H.-D.; Nemiroski, A.; Tricard, S.; Ellerbee, A.K.; Soh, S.; Whitesides, G.M. Noncontact orientation of objects in three-dimensional space using magnetic levitation. Proc. Natl. Acad. Sci. USA 2014, 111, 12980-12985. [CrossRef]

41. Winkleman, A.; Gudiksen, K.L.; Ryan, D.; Whitesides, G.M.; Greenfield, D.; Prentiss, M. A magnetic trap for living cells suspended in a paramagnetic buffer. Appl. Phys. Lett. 2004, 85, 2411-2413. [CrossRef]

42. Kimura, T.; Sato, Y.; Kimura, F.; Iwasaka, M.; Ueno, S. Micropatterning of Cells Using Modulated Magnetic Fields. Langmuir 2005, 21, 830-832. [CrossRef]

43. Wakayama, N.I.; Ataka, M.; Abe, H. Effect of a magnetic field gradient on the crystallization of hen lysozyme. J. Cryst. Growth 1997, 178, 653-656. [CrossRef]

44. Lin, S.-X.; Zhou, M.; Azzi, A.; Xu, G.-J.; Wakayama, N.I.; Ataka, M. Magnet Used for Protein Crystallization: Novel Attempts to Improve the Crystal Quality. Biochem. Biophys. Res. Commun. 2000, 275, 274-278. [CrossRef]

45. Sazaki, G. Crystal quality enhancement by magnetic fields. Prog. Biophys. Mol. Biol. 2009, 101, 45-55. [CrossRef]

46. Nakamura, A.; Ohtsuka, J.; Miyazono, K.; Yamamura, A.; Kubota, K.; Hirose, R.; Hirota, N.; Ataka, M.; Sawano, Y.; Tanokura, M. Improvement in Quality of Protein Crystals Grown in a High Magnetic Field Gradient. Cryst. Growth Des. 2012, 12, 1141-1150. [CrossRef]

47. Chernov, A.A. Modern Crystallography III Crystal Growth; Springer-Verlag: Berlin, Germany, 1984.

48. Nakada, T.; Sazaki, G.; Miyashita, S.; Durbin, S.D.; Komatsu, H. Direct AFM observations of impurity effects on a lysozyme crystal. J. Cryst. Growth 1999, 196, 503-510. [CrossRef]

49. Dold, P.; Ono, E.; Tsukamoto, K.; Sazaki, G. Step velocity in tetragonal lysozyme growth as a function of impurity concentration and mass transport conditions. J. Cryst. Growth 2006, 293, 102-109. [CrossRef]

50. McPherson, A.; DeLucas, L.J. Microgravity protein crystallization. NPJ Microgravity 2015, 1, 15010. [CrossRef]

51. Nakamura, A.; Ohtsuka, J.; Kashiwagi, T.; Numoto, N.; Hirota, N.; Ode, T.; Okada, H.; Nagata, K.; Kiyohara, M.; Suzuki, E.; et al. In-situ and real-time growth observation of high-quality protein crystals under quasi-microgravity on earth. Sci. Rep. 2016, 6, 22127. [CrossRef] [PubMed]

52. Weiss, A.; Witte, H. Magnetochemie; Verlag Chemie GmbH: Weinheim/Bergstr, Germany, 1973; (Japanease Translation). 
53. Yamato, M.; Aoki, H.; Kimura, T.; Yamamoto, I.; Ishikawa, F.; Yamaguchi, M.; Tobita, M. Determination of anisotropic diamagnetic susceptibility of polymeric fibers suspended in liquid. Jpn. J. Appl. Phys. Part 1 Regul. Pap. Short Notes Rev. Pap. 2001, 40, 2237-2240. [CrossRef]

54. Sugiyama, J.; Chanzy, H.; Maret, G. Orientation of cellulose microcrystals by strong magnetic fields. Macromolecules 1992, 25, 4232-4234. [CrossRef]

55. Frka-Petesic, B.; Sugiyama, J.; Kimura, S.; Chanzy, H.; Maret, G. Negative Diamagnetic Anisotropy and Birefringence of Cellulose Nanocrystals. Macromolecules 2015, 48, 8844-8857. [CrossRef]

56. Nye, J.F. Physical Properties of Crystals: Their Representation by Tensors and Matrices; Clarendon Press: Oxford, UK, 1985.

57. Kimura, F.; Kimura, T. Magnetically textured powders-An alternative to single-crystal and powder X-ray diffraction methods. CrystEngComm 2018, 20, 861-872. [CrossRef]

58. Takahashi, T.; Murayama, T.; Higuchi, A.; Awano, H.; Yonetake, K. Aligning vapor-grown carbon fibers in polydimethylsiloxane using dc electric or magnetic field. Carbon N. Y. 2006, 44, 1180-1188. [CrossRef]

59. Piao, G.; Kimura, F.; Takahashi, T.; Moritani, Y.; Awano, H.; Nimori, S.; Tsuda, K.; Yonetake, K.; Kimura, T. Alignment and Micropatterning of Carbon Nanotubes in Polymer Composites Using Modulated Magnetic Field. Polym. J. 2007, 39, 589-592. [CrossRef]

60. Lv, F.; Xu, L.; Xu, Z.; Fu, L.; Zhang, Y. Fabrication and characterization of the orientated MMT/PI composite films via relatively low magnetic field. J. Appl. Polym. Sci. 2015, 132, 41224/1-41224/8. [CrossRef]

61. Ma, C.; Liu, H.-Y.; Du, X.; Mach, L.; Xu, F.; Mai, Y.-W. Fracture resistance, thermal and electrical properties of epoxy composites containing aligned carbon nanotubes by low magnetic field. Compos. Sci. Technol. 2015, 114, 126-135. [CrossRef]

62. Ciambella, J.; Stanier, D.C.; Rahatekar, S.S. Magnetic alignment of short carbon fibres in curing composites. Compos. Part B Eng. 2017, 109, 129-137. [CrossRef]

63. Pelligra, C.I.; Majewski, P.W.; Osuji, C.O. Large area vertical alignment of $\mathrm{ZnO}$ nanowires in semiconducting polymer thin films directed by magnetic fields. Nanoscale 2013, 5, 10511. [CrossRef]

64. Mauter, M.S.; Elimelech, M.; Osuji, C.O. Nanocomposites of Vertically Aligned Single-Walled Carbon Nanotubes by Magnetic Alignment and Polymerization of a Lyotropic Precursor. ACS Nano 2010, 4, 6651-6658. [CrossRef] [PubMed]

65. Kawai, T.; Iijima, R.; Yamamoto, Y.; Kimura, T. Crystal orientation of $\beta$-phase isotactic polypropylene induced by magnetic orientation of N,N'-dicyclohexyl-2,6-naphthalenedicarboxamide. Polymer (Guildf) 2002, 43, 7301-7306. [CrossRef]

66. Takahashi, T.; Higuchi, A.; Awano, H.; Yonetake, K.; Kikuchi, T. Oriented Crystallization of Polycarbonate by Vapor Grown Carbon Fiber and its Application. Polym. J. 2005, 37, 887-893. [CrossRef]

67. Yamato, M.; Kudo, Y.; Takahashi, K.; Watanabe, K.; Kawamoto, N. Magnetic Alignment of Poly(L-lactic acid) Containing a Nucleating Agent. Chem. Lett. 2011, 40, 765-767. [CrossRef]

68. Timbrell, V. Alignment of carbon and other man-made fibers by magnetic fields. J. Appl. Phys. 1972, 43, 4839-4840. [CrossRef]

69. Fujiwara, M.; Oki, E.; Hamada, M.; Tanimoto, Y.; Mukouda, I.; Shimomura, Y. Magnetic Orientation and Magnetic Properties of a Single Carbon Nanotube. J. Phys. Chem. A 2001, 105, 4383-4386. [CrossRef]

70. Choi, E.S.; Brooks, J.S.; Eaton, D.L.; Al-Haik, M.S.; Hussaini, M.Y.; Garmestani, H.; Li, D.; Dahmen, K. Enhancement of thermal and electrical properties of carbon nanotube polymer composites by magnetic field processing. J. Appl. Phys. 2003, 94, 6034-6039. [CrossRef]

71. Goetz, A. Production of "colloidal single crystals". Phys. Rev. 1934, 45, 282-283. [CrossRef]

72. Kim, J.E.; Han, T.H.; Lee, S.H.; Kim, J.Y.; Ahn, C.W.; Yun, J.M.; Kim, S.O. Graphene oxide liquid crystals. Angew. Chemie Int. Ed. 2011, 50, 3043-3047. [CrossRef]

73. Wu, L.; Ohtani, M.; Takata, M.; Saeki, A.; Seki, S.; Ishida, Y.; Aida, T. Magnetically Induced Anisotropic Orientation of Graphene Oxide Locked by in Situ Hydrogelation. ACS Nano 2014, 8, 4640-4649. [CrossRef] [PubMed]

74. Tobita, M.; Tateda, S.; Kimura, T.; Yamato, M. Magnetically oriented boron nitride-filled highly thermally conductive sheet. Jpn. Kokai Tokkyo Koho 2002, 10.

75. Suzuki, T.S.; Uchikoshi, T.; Sakka, Y. Effect of sintering additive on crystallographic orientation in AlN prepared by slip casting in a strong magnetic field. J. Eur. Ceram. Soc. 2009, 29, 2627-2633. [CrossRef] 
76. Uyeda, C.; Takeuchi, T.; Yamagishi, A.; Tsuchiyama, A.; Yamanaka, T.; Date, M. Diamagnetic anisotropy of sheetsilicates. Phys. Chem. Miner. 1993, 20,369-374. [CrossRef]

77. Takahashi, T.; Ohkubo, T.; Ikeda, Y. Montmorillonite alignment induced by magnetic field: Evidence based on the diffusion anisotropy of water molecules. J. Colloid Interface Sci. 2006, 299, 198-203. [CrossRef]

78. Kitajima, S.; Matsuda, M.; Yamato, M.; Tominaga, Y. Anisotropic ionic conduction in composite polymer electrolytes filled with clays oriented by a strong magnetic field. Polym. J. 2013, 45, 738-743. [CrossRef]

79. Uyeda, C.; Takeuchi, T.; Yamagishi, A.; Date, M. Diamagnetic orientation of clay mineral grains. J. Phys. Soc. Japan 1991, 60, 3234-3237. [CrossRef]

80. Abrahamsson, C.; Nordstierna, L.; Nordin, M.; Dvinskikh, S.V.; Nyden, M.; Nydén, M. Magnetic orientation of nontronite clay in aqueous dispersions and its effect on water diffusion. J. Colloid Interface Sci. 2015, 437, 205-210. [CrossRef] [PubMed]

81. Liu, M.; Ishida, Y.; Ebina, Y.; Sasaki, T.; Hikima, T.; Takata, M.; Aida, T. An anisotropic hydrogel with electrostatic repulsion between cofacially aligned nanosheets. Nature 2015, 517, 68-72. [CrossRef]

82. Nakayama, M.; Kajiyama, S.; Kumamoto, A.; Nishimura, T.; Ikuhara, Y.; Yamato, M.; Kato, T. Stimuli-responsive hydroxyapatite liquid crystal with macroscopically controllable ordering and magneto-optical functions. Nat. Commun. 2018, 9, 568. [CrossRef]

83. Matsunaga, C.; Uchikoshi, T.; Suzuki, T.S.; Sakka, Y.; Matsuda, M. Orientation control of mordenite zeolite in strong magnetic field. Microporous Mesoporous Mater. 2012, 151, 188-194. [CrossRef]

84. Miwa, Y.; Kawada, S.; Kimura, M.; Omiya, S.; Kubodera, N.; Ando, A.; Suzuki, T.S.; Uchikoshi, T.; Sakka, Y. Processing and enhanced piezoelectric properties of highly oriented compositionally modified $\mathrm{Pb}(\mathrm{Zr}, \mathrm{Ti}) \mathrm{O} 3$ ceramics fabricated by magnetic alignment. Appl. Phys. Express 2015, 8, 1-4. [CrossRef]

85. Kimura, T.; Yoshino, M.; Yamane, T.; Yamato, M.; Tobita, M. Uniaxial alignment of the smallest diamagnetic susceptibility axis using time-dependent magnetic fields. Langmuir 2004, 20, 5669-5672. [CrossRef]

86. Genoud, J.-Y.; Staines, M.; Mawdsley, A.; Manojlovic, V.; Quinton, W. Biaxially textured YBCO coated tape prepared using dynamic magnetic grain alignment. Supercond. Sci. Technol. 1999, 12, 663-671. [CrossRef]

87. Kimura, T.; Yoshino, M. Three-dimensional crystal alignment using a time-dependent elliptic magnetic field. Langmuir 2005, 21, 4805-4808. [CrossRef]

88. Kimura, T.; Kimura, F.; Yoshino, M. Magnetic alteration of crystallite alignment converting powder to a pseudo single crystal. Langmuir 2006, 22, 3464-3466. [CrossRef]

89. Horii, S.; Yamaki, M.; Shimoyama, J. Rare-Earth-Dependent Tri-axial Magnetic Anisotropies and Growth Conditions in REBa $2 \mathrm{Cu} 4 \mathrm{O} 8$ Related content Growth of (Y1xCax)Ba2Cu4O8 in ambient pressure and its tri-axial magnetic alignment. Jpn. J. Appl. Phys. 2012, 51, 010107/1-010107/7. [CrossRef]

90. Nakatsuka, N.; Yasuda, H.; Nagira, T.; Yoshiya, M. Three-dimensional alignment of FeSi2 with orthorhombic symmetry by an anisotropic magnetic field. J. Phys. Conf. Ser. 2009, 165, 012021. [CrossRef]

91. Kimura, F.; Oshima, W.; Matsumoto, H.; Uekusa, H.; Aburaya, K.; Maeyama, M.; Kimura, T. Single crystal structure analysis via magnetically oriented microcrystal arrays. CrystEngComm 2014, 16, 6630-6634. [CrossRef]

92. Kusumi, R.; Kimura, F.; Song, G.; Kimura, T. Chemical shift tensor determination using magnetically oriented microcrystal array (MOMA): 13C solid-state CP NMR without MAS. J. Magn. Reson. 2012, 223, 68-72. [CrossRef]

93. Teranishi, S.; Kusumi, R.; Kimura, F.; Kimura, T.; Aburaya, K.; Maeyama, M. Biaxial magnetic orientation of zinc citrate as nucleating agent of poly(L-lactic acid). Chem. Lett. 2017, 46, 830-832. [CrossRef]

94. Horii, S.; Arimoto, I.; Doi, T. Linear drive type of modulated rotating magnetic field for a continuous process of three-dimensional crystal orientation. J. Ceram. Soc. Japan 2018, 126, 885-888. [CrossRef]

95. Moore, J.S.; Stupp, S.I. Orientation dynamics of main-chain liquid crystal polymers. 2. Structure and kinetics in a magnetic field. Macromolecules 1987, 20, 282-293. [CrossRef]

96. Kimura, T.; Yamato, M.; Koshimizu, W.; Koike, M.; Kawai, T. Magnetic Orientation of Polymer Fibers in Suspension. Langmuir 2000, 16, 858-861. [CrossRef]

97. Wu, C.; Li, S.; Sassa, K.; Chino, Y.; Hattori, K.; Asai, S. Theoretical Analysis on Crystal Alignment of Feeble Magnetic Materials under High Magnetic Field. Mater. Trans. 2005, 46, 1311-1317. [CrossRef]

98. Takayama, T.; Ikezoe, Y.; Kaihatsu, T.; Uetake, H.; Hirota, N.; Kitazawa, K. Alignments of feeble magnetic particles under high magnetic fields. Trans. Mater. Res. Soc. Japan 2002, 27, 43-46. 
99. Hirota, N.; Ando, T.; Tanaka, R.; Wada, H.; Sakka, Y. Control of lattice spacing in a triangular lattice of feeble magnetic particles formed by induced magnetic dipole interactions. Sci. Technol. Adv. Mater. 2009, 10, 014608. [CrossRef]

100. Skjeltorp, A.T. One-and Two-Dimensional Crystallization of Magnetic Holes. Phys. Rev. Lett. 1983, 51, 2306-2309. [CrossRef]

101. Ando, T.; Hirota, N.; Wada, H. Numerical simulation of chainlike cluster movement of feeble magnetic particles by induced magnetic dipole moment under high magnetic fields. Sci. Technol. Adv. Mater. 2009, 10, 014609. [CrossRef]

102. Martin, J.E.; Anderson, R.A.; Odinek, J.; Adolf, D.; Williamson, J. Controlling percolation in field-structured particle composites: Observations of giant thermoresistance, piezoresistance, and chemiresistance. Phys. Rev. B 2003, 67, 094207. [CrossRef]

103. Yamato, M.; Obayashi, S.; Nishiyama, T.; Horibe, H.; Takahashi, K.; Watanabe, K. The effect of the structural order of isotactic polypropylene containing magnetically aligned nickel particles on its electrical resistivity. Polymer (Guildf) 2014, 55, 6546-6551. [CrossRef]

104. Sun, M.; Dai, B.; Liu, K.; Yao, K.; Zhao, J.; Lyu, Z.; Wang, P.; Ding, Y.; Yang, L.; Han, J.; et al. Enhancement in thermal conductivity of polymer composites using aligned diamonds coated with superparamagnetic magnetite. Compos. Sci. Technol. 2018, 164, 129-135. [CrossRef]

105. Martin, J.; Venturini, E.; Odinek, J.; Anderson, R. Anisotropic magnetism in field-structured composites. Phys. Rev. E 2000, 61, 2818-2830. [CrossRef]

106. Chung, J.-Y.; Lee, J.-G.; Baek, Y.-K.; Shin, P.-W.; Kim, Y.-K. Magnetic field-induced enhancement of thermal conductivities in polymer composites by linear clustering of spherical particles. Compos. Part B Eng. 2018, 136, 215-221. [CrossRef]

107. Li, W.; Yu, L.; Zhu, Y.; Hua, D. External Magnetic Field Induced Percolation in Polyvinylidene Fluoride and Nickel Composites. J. Phys. Chem. C 2010, 114, 14004-14007. [CrossRef]

108. Mietta, J.L.; Ruiz, M.M.; Antonel, P.S.; Perez, O.E.; Butera, A.; Jorge, G.; Negri, R.M. Anisotropic Magnetoresistance and Piezoresistivity in Structured Fe 3 O 4 -Silver Particles in PDMS Elastomers at Room Temperature. Langmuir 2012, 28, 6985-6996. [CrossRef]

109. Kchit, N.; Bossis, G. Piezoresistivity of magnetorheological elastomers. J. Phys. Condens. Matter 2008, 20, 204136. [CrossRef]

110. Jin, S.; Tiefel, T.N.; Wolfe, R. Directionally-conductive, optically-transparent composites by magnetic alignment. IEEE Trans. Magn. 1992, 28, 2211-2213. [CrossRef]

111. Knaapila, M.; Høyer, H.; Kjelstrup-Hansen, J.; Helgesen, G. Transparency Enhancement for Photoinitiated Polymerization (UV Curing) through Magnetic Field Alignment in a Piezoresistive Metal/Polymer Composite. ACS Appl. Mater. Interfaces 2014, 6, 3469-3476. [CrossRef] [PubMed]

112. Li, Y.; Mehra, N.; Ji, T.; Yang, X.; Mu, L.; Gu, J.; Zhu, J. The stiffness-thermal conduction relationship at the composite interface: The effect of particle alignment on the long-range confinement of polymer chains monitored by scanning thermal microscopy. Nanoscale 2018, 10, 1695-1703. [CrossRef]

113. Kamiyama, S.; Okubo, M.; Fujisawa, F. Recent developments of technology in magnetic fluid experiments. Exp. Therm. Fluid Sci. 1992, 5, 641-651. [CrossRef]

114. Kopcansky, P.; Timko, M.; Koneracka, M.; Zavisova, V.; Kubovcikova, M.; Molcan, M.; Balejcikova, L.; Tomasovicova, N.; Rajnak, M.; Gdovinova, V. Magnetic Fluids and Their Complex Systems. In Springer Proceedings in Physics; Springer: Berlin, Germany, 2018; Volume 197, pp. 151-184.

115. Vshivkov, S.A.; Avvakumova, A.S. Effect of magnetic field on the rheological properties of poly(ethylene glycol) and poly(dimethylsiloxane) mixtures with aerosil and iron nanoparticles. Polym. Sci. Ser. A 2017, 59, 764-771. [CrossRef]

116. Miyake, S. Applications of magnetic fluid seals to vacuum. SHINKU 1985, 28, 483-493. [CrossRef]

117. Stanley, H.E. Introduction to Phase Transitions and Critical Phenomena; Oxford University Press: New York, NY, USA, 1971.

118. Wang, S.; Tozaki, K.-I.; Hayashi, H.; Inaba, H. Magnetic effect on the phase transitions of n-docosane by means of a high resolution and super-sensitive DSC. Thermochim. Acta 2013, 571, 8-14. [CrossRef]

119. Inaba, H.; Tozaki, K.-I.; Hayashi, H.; Quan, C.; Nemoto, N.; Kimura, T. Magnetic effect on the phase transitions of n-C32H66 measured by high resolution and super-sensitive DSC. Phys. B Condens. Matter 2002, 324, 63-71. [CrossRef] 
120. Kimura, T. Orientation-dependent Magneto-Clapeyron Equation. Jpn. J. Appl. Phys. 2001, 40, 6818. [CrossRef]

121. Gopinadhan, M.; Majewski, P.W.; Choo, Y.; Osuji, C.O. Order-Disorder Transition and Alignment Dynamics of a Block Copolymer Under High Magnetic Fields by In Situ X-Ray Scattering. Phys. Rev. Lett. 2013, 110, 078301. [CrossRef]

122. Francescangeli, O.; Vita, F.; Fauth, F.; Samulski, E.T. Extraordinary Magnetic Field Effect in Bent-Core Liquid Crystals. Phys. Rev. Lett. 2011, 107, 207801. [CrossRef]

123. Vshivkov, S.A.; Zhernov, I.V.; Nadol'skii, A.L.; Mizyov, A.S. Effect of magnetic field on phase transitions in solutions and melts of flexible polymers. Polym. Sci. Ser. A 2017, 59, 465-472. [CrossRef]

124. Sata, H.; Kimura, T.; Ogawa, S.; Yamato, M.; Ito, E. Magnetic orientation of poly(ethylene-2,6-naphthalate). Polymer (Guildf). 1996, 37, 1879-1882. [CrossRef]

125. Aoki, H.; Yamato, M.; Kimura, T. Magnetic Alignment of Poly(carbonate). Chem. Lett. 2001, 30, $1140-1141$. [CrossRef]

126. Kimura, T.; Kawai, T.; Sakamoto, Y. Magnetic orientation of poly(ethylene terephthalate). Polymer (Guildf) 2000, 41, 809-812. [CrossRef]

127. Naga, N.; Ishikawa, G.; Noguchi, K.; Takahashi, K.; Watanabe, K.; Yamato, M. Magnetic-field induced alignment of low molecular weight polyethylene. Polymer (Guildf) 2013, 54, 784-790. [CrossRef]

128. Kawai, T.; Kimura, T. Magnetic orientation of isotactic polypropylene. Polymer (Guildf) 2000, 41, 155-159. [CrossRef]

129. Ezure, H.; Kimura, T.; Ogawa, S.; Ito, E. Magnetic Orientation of Isotactic Polystyrene. Macromolecules 1997, 30, 3600-3605. [CrossRef]

130. Ebert, F.; Thurn-Albrecht, T. Controlling the Orientation of Semicrystalline Polymers by Crystallization in Magnetic Fields. Macromolecules 2003, 36, 8685-8694. [CrossRef]

131. Naga, N.; Saito, Y.; Noguchi, K.; Takahashi, K.; Watanabe, K.; Yamato, M. Magnetic-field-induced alignment of syndiotactic polystyrene. Polym. J. 2016, 48, 709-714. [CrossRef]

132. Suzuki, K.; Yamato, M.; Hirota, N. Alignment of Nylon 6 by Melt Crystallization in a High Magnetic Field. Kobunshi Ronbunshu 2014, 71, 112-118. [CrossRef]

133. Nakayama, R.; Ikake, H.; Kurita, K.; Shimizu, S.; Kurumi, S.; Suzuki, K.; Takahashi, K.; Watanabe, K. Preparation of Poly(lactic acid) Films in a Magnetic Field and their Microstructure. Kobunshi Ronbunshu 2015, 72, 661-666. [CrossRef]

134. Zhang, M.; Guo, B.-H.; Xu, J. A Review on Polymer Crystallization Theories. Crystals 2017, 7, 4. [CrossRef]

135. Yamato, M.; Kimura, T. Relationship between magnetic alignment and the crystallization condition of isotactic polystyrene. Sci. Technol. Adv. Mater. 2006, 7, 337-341. [CrossRef]

136. Sata, H.; Kimura, T.; Ogawa, S.; Ito, E. Magnetic orientation of poly(ethylene 2,6-naphthalate) during crystallization from melt. Polymer (Guildf) 1998, 39, 6325-6330. [CrossRef]

137. Park, C.; Yoon, J.; Thomas, E.L. Enabling nanotechnology with self assembled block copolymer patterns. Polymer (Guildf) 2003, 44, 6725-6760. [CrossRef]

138. Grigorova, T.; Pispas, S.; Hadjichristidis, N.; Thurn-Albrecht, T. Magnetic Field Induced Orientation in Diblock Copolymers with One Crystallizable Block. Macromolecules 2005, 38, 7430-7433. [CrossRef]

139. Gopinadhan, M.; Majewski, P.W.; Osuji, C.O. Facile Alignment of Amorphous Poly(ethylene oxide) Microdomains in a Liquid Crystalline Block Copolymer Using Magnetic Fields: Toward Ordered Electrolyte Membranes. Macromolecules 2010, 43, 3286-3293. [CrossRef]

140. Tomikawa, N.; Lu, Z.; Itoh, T.; Imrie, C.T.; Adachi, M.; Tokita, M.; Watanabe, J. Orientation of Microphase-Segregated Cylinders in Liquid Crystalline Diblock Copolymer by Magnetic Field. Jpn. J. Appl. Phys. 2005, 44, L711-L714. [CrossRef]

141. Feng, X.; Tousley, M.E.; Cowan, M.G.; Wiesenauer, B.R.; Nejati, S.; Choo, Y.; Noble, R.D.; Elimelech, M.; Gin, D.L.; Osuji, C.O. Scalable Fabrication of Polymer Membranes with Vertically Aligned $1 \mathrm{~nm}$ Pores by Magnetic Field Directed Self-Assembly. ACS Nano 2014, 8, 11977-11986. [CrossRef]

142. Hamley, I.W.; Castelletto, V.; Lu, Z.B.; Imrie, C.T.; Itoh, T.; Al-Hussein, M. Interplay between Smectic Ordering and Microphase Separation in a Series of Side-Group Liquid-Crystal Block Copolymers. Macromolecules 2004, 37, 4798-4807. [CrossRef] 
143. Osuji, C.; Ferreira, P.J.; Mao, G.; Ober, C.K.; Vander Sande, J.B.; Thomas, E.L. Alignment of Self-Assembled Hierarchical Microstructure in Liquid Crystalline Diblock Copolymers Using High Magnetic Fields. Macromolecules 2004, 37, 9903-9908. [CrossRef]

144. Majewski, P.W.; Gopinadhan, M.; Jang, W.-S.; Lutkenhaus, J.L.; Osuji, C.O. Anisotropic Ionic Conductivity in Block Copolymer Membranes by Magnetic Field Alignment. J. Am. Chem. Soc. 2010, 132, 17516-17522. [CrossRef]

145. Tran, H.; Gopinadhan, M.; Majewski, P.W.; Shade, R.; Steffes, V.; Osuji, C.O.; Campos, L.M. Monoliths of Semiconducting Block Copolymers by Magnetic Alignment. ACS Nano 2013, 7, 5514-5521. [CrossRef]

146. Gopinadhan, M.; Choo, Y.; Osuji, C.O. Strong Orientational Coupling of Block Copolymer Microdomains to Smectic Layering Revealed by Magnetic Field Alignment. ACS Macro Lett. 2016, 5, 292-296. [CrossRef]

147. Gopinadhan, M.; Majewski, P.W.; Beach, E.S.; Osuji, C.O. Magnetic Field Alignment of a Diblock Copolymer Using a Supramolecular Route. ACS Macro Lett. 2012, 1, 184-189. [CrossRef]

148. Majewski, P.W.; Osuji, C.O. Controlled Alignment of Lamellar Lyotropic Mesophases by Rotation in a Magnetic Field. Langmuir 2010, 26, 8737-8742. [CrossRef] [PubMed]

149. Rokhlenko, Y.; Gopinadhan, M.; Osuji, C.O.; Zhang, K.; O’Hern, C.S.; Larson, S.R.; Gopalan, P.; Majewski, P.W.; Yager, K.G. Magnetic Alignment of Block Copolymer Microdomains by Intrinsic Chain Anisotropy. Phys. Rev. Lett. 2015, 115, 258302. [CrossRef] [PubMed]

(C) 2020 by the authors. Licensee MDPI, Basel, Switzerland. This article is an open access article distributed under the terms and conditions of the Creative Commons Attribution (CC BY) license (http://creativecommons.org/licenses/by/4.0/). 